\title{
Glutamate pathway implication in amyotrophic lateral sclerosis: what is the signal in the noise?
}

This article was published in the following Dove Press journal:

Journal of Receptor, Ligand and Channel Research

21 December 2010

Number of times this article has been viewed

\author{
Virginia Le Verche ${ }^{1,3}$ \\ Burcin Ikiz \\ Arnaud Jacquier ${ }^{1,3}$ \\ Serge Przedborski ${ }^{1-3}$ \\ Diane B $\operatorname{Re}^{1,3}$ \\ 'Departments of Neurology, \\ 2Pathology and Cell Biology, and the \\ ${ }^{3}$ Center for Motor Neuron Biology \\ and Disease, Columbia University, \\ New York, NY, USA; ${ }^{4}$ Ms Burcin Ikiz \\ is a graduate student in the program \\ of Neurobiology and Behavior at \\ Columbia University
}

Correspondence: Diane B Re Columbia University, 630 West I68th Street, P\&S 4-40I, New York, 10032, NY, USA

$\mathrm{Tel}+\mathrm{I} 2$ 2 2-305-8689

$\mathrm{Fax}+\mathrm{I} 212-305-5450$

Email dr2240@columbia.edu

\begin{abstract}
The cause of the fatal motor neuron disease, amyotrophic lateral sclerosis (ALS), remains largely unknown. Most cases of ALS are sporadic and, for $\sim 20 \%$ of familial ALS patients, mutations in the superoxide dismutase-1 (SOD1) gene have been identified. Transgenic rodents overexpressing mutant SOD1 emulate the disease and constitute the best ALS animal model so far. Several lines of evidence suggest that ALS is a multifactorial condition. In this review, we discuss the question of the involvement of the glutamate pathways in ALS-induced motor neuron death. As such, we review the data implicating glutamate metabolism alterations, glutamatergic environmental toxins, glutamate transporter/receptor defects, and $\mathrm{Ca}^{2+}$-mediated glutamate toxicity in the etiopathogenesis of ALS. Given the published data, we contend that glutamate-induced neurotoxicity more likely precipitates motor neuron degeneration rather than being the initiating factor of ALS. Furthermore, we propose that glutamate-induced neurotoxicity participates in the ALS deadly molecular cascade only as an executioner to put an end to a series of molecular perturbations that have irreversibly compromised motor neuron function. This could provide an explanation for the modest effect of therapeutic strategies targeting the glutamatergic system, including the only currently FDA-approved ALS treatment, riluzole. As in diseased motor neurons, overwhelming $\mathrm{Ca}^{2+}$ overload may be the converging point for glutamate, endoplasmic reticulum stress, and mitochondrial dysfunctional pathways, and only therapies targeting these simultaneously or targeting the earliest alterations initiating this deleterious cascade may have a real impact on halting ALS progression.
\end{abstract}

Keywords: glutamate, excitotoxicity, amyotrophic lateral sclerosis, glutamate receptors, glutamate transporters, calcium

\section{Overview}

One of the simplest and most abundant molecules of the living, the proteinogenic L-amino acid glutamate, is a major excitatory neurotransmitter of the mammalian central nervous system (CNS). Glutamate belongs to the family of excitatory amino acids (EAAs) and is widely distributed throughout the CNS. Glutamate transmission is implicated in functions as diverse as learning, memory, sensori-motricity, brain development, and endocrine control of peripheral organs. ${ }^{1-3}$ In addition to its role in neurotransmission, glutamate can kill neurons. The first observation of glutamate neurotoxicity was reported by Lucas and Newhouse, ${ }^{4}$ who described that parenteral administration of monosodium L-glutamate to newborn mice triggers retinal cell degeneration. Subsequently, Olney and collaborators ${ }^{5}$ showed that the lesion in immature rodents, caused by L-glutamate, is not restricted to the retina, but extends to central structures such as the hypothalamus, not yet protected by the blood-brain barrier (BBB). Since submit your manuscript $\mid$ www.dovepress.com

Dovepress

DOI: 10.2147/JRLCR.S6504
Journal of Receptor, Ligand and Channel Research 201 I:4 I-22

(C) 20I I Le Verche et al, publisher and licensee Dove Medical Press Ltd. This is an Open Access article which permits unrestricted noncommercial use, provided the original work is properly cited. 
the mechanisms of $\mathrm{Na}^{+}$-dependency of glutamate-induced neuronal depolarization started to be recognized ${ }^{6}$ a few years before, Olney envisioned a possible relationship between the excitatory and the cytotoxic effects of glutamate, thus giving birth to the concept of "excitotoxicity" or excessive stimulation of glutamate receptors (GluRs). ${ }^{7}$

One can wonder whether the attribution of such powerful neurotoxicity to a ubiquitous molecule like glutamate was a regrettable error or was intended by nature. One speculation may be that, originally, it aimed at providing the brain with a cell suicide back-up plan to shut down diseased cells and to protect the integrity of the system. Whatever the answer, the discovery of excitotoxicity stressed the importance of glutamate reuptake after synaptic release not only to maintain the phasic character of neurotransmission but also to guarantee neuronal survival. Excitotoxicity became, thereafter, one of the prime suspects responsible for neurodegeneration in CNS insults. In the literature, there is now a plethora of evidence of increased extracellular glutamate levels and glutamate uptake dysfunction in numerous acute insults, such as ischemia or traumatic brain injury, and in chronic degenerative diseases, such as Huntington's disease, Parkinson's disease, Alzheimer's disease and amyotrophic lateral sclerosis (ALS), ${ }^{8}$ although much more controversial. Even though over the years the excitotoxicity advocates built up a strong case for the involvement of excitotoxic processes in neuronal death associated with acute insults, the situation on chronic neurodegenerative diseases is still murky. ${ }^{9}$ It certainly appears less intuitive to relate excitotoxicity to very diverse, progressive, and selective neurodegenerative processes than to acute focal waves of cell death.

In this review, we will focus on glutamate pathways in the relentless motor neuron (MN) disease, ALS, for which there is abundant literature and which has been reviewed extensively in the past. Here, we will try to give the reader a new take on the debate of glutamate/EAA dysfunction in ALS by providing a critical appraisal of the published data on the topic and by highlighting how an old hypothesis like this may be related to the newest theories on the cellular and molecular mechanisms underlying the ALS neurodegenerative process, such as mRNA defects and non-neuronal cell toxicity. After introducing glutamate/EAA-linked cytotoxic mechanisms and ALS, we will discuss the controversial history of glutamate in ALS with a particular emphasis on glutamate transport alterations, which were the first evidence to put astrocytes and noncell autonomous toxic processes at center stage in ALS. Then, we will review how GluR specificities and mRNA modifications are related to a possible peculiar vulnerability of MNs to excitotoxicity and the development of MN diseases such as ALS. Behind the mask of glutamate or other toxic processes such as oxidative stress, many believe that the real $\mathrm{MN}$ terminator is $\mathrm{Ca}^{2+}$. We will examine how properties associated with $\mathrm{Ca}^{2+}$ attempt to explain the selective degeneration of MNs in ALS and how glutamate-associated $\mathrm{Ca}^{2+}$ overloads are related to endoplasmic reticulum (ER) stress and mitochondrial defects, two alternate pathogenic mechanisms that may account for MN demise in ALS. Our final objective is to come up with the clearest message on the level and degree of implication of glutamate dysfunction in ALS and on the perspectives that it possibly opens for therapy.

\section{Excitatory amino acid-associated death processes}

Excitotoxicity is defined as cell death resulting from excessive stimulation of GluRs, which is hypothesized to follow increased release or decreased reuptake of synaptic glutamate. However, which characteristics of GluRs may underlie this deadly capacity?

Glutamatergic receptors are classified into ion channelcoupled or ionotropic receptors (NMDA, AMPA, and kainate $[\mathrm{KA}]$ ) and $\mathrm{G}$ protein-coupled or metabotropic receptors (class I, II, and III). Fast excitatory transmission is mediated by AMPA/KA receptors through the entry of $\mathrm{Na}^{+}$and $\mathrm{K}^{+}$ions triggering the instantaneous depolarization of neurons and the removal of NMDA receptor $\mathrm{Mg}^{2+}$ block. NMDA receptors are responsible for a slower and longer-lasting transmission and are characterized by their high permeability for $\mathrm{Ca}^{2+}$, as well as $\mathrm{Na}^{+}$and $\mathrm{K}^{+}$. Initially, NMDA receptors were considered as the main source of extracellular $\mathrm{Ca}^{2+}$ in neurons. Later, some specific forms of AMPA receptors lacking the GluR2 subunit were also identified as $\mathrm{Ca}^{2+}$ permeable. ${ }^{10}$ The properties of GluR2 are generated post-transcriptionally by RNA editing at the Q/R site by the enzyme called adenosine deaminase acting on RNA 2 (ADAR2) leading to a substitution of the neutrally charged glutamine (Q) amino acid by a positively charged arginine (R). ${ }^{11,12}$ Therefore, AMPA receptors containing an unedited GluR2 subunit are also $\mathrm{Ca}^{2+}$ permeable. Diversity of AMPA GluR is also obtained by alternative splicing of subunits at the flip/flop and/or C terminal sites leading to differential desensitization properties. ${ }^{13,14}$ Finally, metabotropic receptors are responsible for a long-lasting modulation of glutamatergic transmission through G-protein-regulated enzymes producing several second messengers, such as cyclic adenosine monophosphate or $\mathrm{Ca}^{2+} .{ }^{14}$ 
Pioneer in vitro studies, aimed at unraveling the mechanisms of excitotoxicity, have shown that GluR-mediated neurotoxicity can be separated into two components, based on differential time course and ionic dependence: an acute limited and a delayed massive toxicity, underlain by $\mathrm{Na}^{+}$and $\mathrm{Ca}^{2+}$ influx, respectively. ${ }^{15,16}$ The acute neurotoxicity is characterized by neuronal swelling, and ultimately, lysis. This can be prevented by removal, from the culture medium, of $\mathrm{Na}^{+}$and $\mathrm{Cl}^{-}$responsible for massive water entry during GluR cationic channel opening. In contrast, the delayed neurotoxicity was demonstrated to be supported by $\mathrm{Ca}^{2+}$ entry and its progression is not altered by prevention of the acute excitotoxicity. Among neurotransmitter receptors, permeability to $\mathrm{Ca}^{2+}$ being the privilege of GluRs, the lion's share of attention in excitotoxicity research has been paid to the $\mathrm{Ca}^{2+}$-mediated delayed form of glutamate neurotoxicity, which can be more easily dissociated from the simple neuronal excitation. Subsequently, the necessity of prolonged intraneuronal $\mathrm{Ca}^{2+}$ increase to produce neuronal damage was reported. ${ }^{17}$ It has also been documented that voltage-dependent $\mathrm{Ca}^{2+}$ channels, reversal of the $\mathrm{Na}^{+} / \mathrm{Ca}^{2+}$ exchanger and group I metabotropic receptors through inositol tri-phosphate-mediated $\mathrm{ER} \mathrm{Ca}^{2+}$ release may contribute to the sustained $\mathrm{Ca}^{2+}$ elevations during excitotoxic processes. ${ }^{18}$ Excess free intracellular $\mathrm{Ca}^{2+}$ is then thought to trigger a destructive cascade via activation of proteases, phospholipases, endonucleases, and pro-oxidant enzymes leading ultimately to oxidative stress and neuronal death. ${ }^{19}$

Since consistent evidence of increased glutamate or other EAA levels have not been provided in chronic neurodegenerative diseases and even as physiological concentrations of glutamate become toxic during energy failure, ${ }^{20}$ an alternative concept referred to as "secondary" or "slow-onset excitotoxicity" has developed over the years. According to this theory, in absence of any alteration of its extracellular level, glutamate may induce the death of specific neuronal populations that were hypersensitized by a genetic, endogenous or exogenous metabolic factor. ${ }^{9}$ Impairment of energy metabolism, trophic support, oxidative stress, or alteration in GluR ionic permeability may constitute examples of such factors leading to an exacerbated neuronal vulnerability to normal glutamate levels. This hypothesis may appear tantalizing by providing some clues to why distinct neuronal populations are selectively degenerating in various chronic nervous system disorders.

Of note, the overstimulation of GluRs is not the only pathway through which increased extracellular glutamate concentrations were shown to be cytotoxic. A form of toxicity resulting from the inhibition of the $\mathrm{xc}^{-}$cystine-glutamate antiporter by high extracellular glutamate levels has been described in vitro. ${ }^{21,22}$ Termed "oxidative glutamate toxicity", this type of cell death is underlain by an impairment of cystine uptake, leading to glutathione depletion and oxidative stress, cystine being the limiting factor in glutathione synthesis. Interestingly, it has been suggested that oxidative glutamate toxicity may be part of the excitotoxicity cascade. ${ }^{23}$ However, the relevance of this mechanism for mature neurons remains uncertain as this antiporter is mainly expressed by astrocytes and by immature neurons only. ${ }^{24}$

\section{Amyotrophic lateral sclerosis}

ALS has been described by many as one of the most dreadful diseases of the human condition. This midlife-onset paralytic disorder, inexorably lethal in 2 to 5 years after diagnosis, progresses very aggressively to lock an intellectually preserved human being in a motionless body. Only the occulomotor and continence controls are usually spared. ${ }^{25}$ The incidence of ALS is about 1 to 2 in $100,000 .{ }^{26}$ Pathological analyses have revealed that ALS is characterized by the progressive degeneration of the upper MNs or the lower MNs or both. ${ }^{27}$ In the vast majority of cases ( $\sim 90 \%)$, ALS is documented as a sporadic condition, ie, of unknown etiology. In the remaining $\sim 10 \%$ of ALS cases associated with a familial history, mutations in several genes have been identified (for review $\left.\mathrm{see}^{28}\right)$. Clinically, familial and sporadic ALS are impossible to tell apart. The most commonly mutated genes in familial ALS, accounting for approximately $20 \%$ of all the cases, is the gene encoding for the enzyme superoxide dismutase-1 (SOD1). ${ }^{28}$ To date, more than 150 mutations in this enzyme have been identified in ALS families (http://www.alsod.org) even if the pathogenicity of two of them has recently been challenged. ${ }^{29}$ SOD1 is a ubiquitously expressed, abundant cytosolic enzyme ${ }^{30}$ whose role is to catalyze the dismutation of superoxide into oxygen and hydrogen peroxide. Transgenic mice expressing either catalytically active SOD1 mutants ${ }^{31,32}$ or catalytically inactive SOD1 mutants ${ }^{33,34}$ develop a paralytic disorder emulating the clinical and neuropathological hallmarks of human ALS. In contrast, transgenic mice expressing high levels of wild-type human SOD1stay healthy, ${ }^{32}$ even if several neuromuscular junction abnormalities were described in 24 month-old mice suggesting a premature aging of the nervous system as seen in Down's syndrome..$^{35}$ Based on these observations and others, the consensus now is that it is through a toxic gain-of-function effect that mutant SOD1 causes MN degeneration. However, despite 15 years of extensive work on this only available animal model of ALS, 
the nature of the mutant SOD1 acquired deleterious effect remains elusive. To date, it has been proposed that mutant SOD1 cytotoxicity involves different mechanisms including excitotoxicity, ${ }^{36}$ glutamate transporter failure, ${ }^{37}$ oxidative stress, ${ }^{38,39}$ protein aggregation, ${ }^{40}$ aberrant protein-protein interactions, ${ }^{41}$ decreased binding affinity for zinc, ${ }^{42}$ mitochondrial dysfunction, ${ }^{43,44}$ ER stress, ${ }^{45}$ and apoptosis,,${ }^{46,47}$ none of which are mutually exclusive. Pertinent to the possible implication of excitotoxicity in a MN disease like ALS is the fact that glutamate appears to be a key neurotransmitter in the human motor system. Indeed, MNs may receive massive glutamatergic innervation from the corticospinal tracts, ${ }^{48}$ the spinal excitatory interneuronal pathways, ${ }^{49}$ and the corticocortical association pathways. ${ }^{50}$ On the other hand, during these last few years, an important insight made in ALS SOD1 rodents is the notion that mutant SOD1 in both MNs and non-neuronal cells, especially glial cells like astrocytes and microglia contribute to the disease process in vivo ${ }^{51-55}$ and that in vitro mutant SOD1 expression in astrocytes is sufficient to selectively kill otherwise healthy $\mathrm{MNs}^{56-58}$ through a soluble toxic mechanism. ${ }^{57}$ Very recently, ALS research has turned its attention toward RNA metabolism alterations as a possible unifying cause of the degenerative process following the identification, in familial and sporadic patients, of mutations in different RNA processing proteins such as TAR DNA-binding protein 43 (TDP43) (5-61 $^{6}$ and fused in sarcoma/translated in liposarcoma (FUS/TLS). ${ }^{62,63}$ Mutations in the TDP-43 and FUS/TLS genes account for 5\% and 4\%, respectively, of familial ALS patients. It can be expected that the development of animal models of these new mutations may help ALS research leap forward in the near future.

\section{Glutamate and ALS: history and controversies Glutamate levels in ALS patients and animal models: the roots of the debate}

The first publication found in PubMed describing an investigation related to glutamate in ALS was published in 1978. ${ }^{64}$ This study, aimed at comparing amino acid levels in 12 ALS patients with those of 12 control patients, matched for age, sex, and severity of disability (affected by diverse paralytic disorders), reports that glutamate concentrations are unchanged in cerebrospinal fluid (CSF) and not significantly increased in serum and urine, suggesting that there is no glutamate-associated specific signature in ALS patients. However, this was challenged a decade later, when plasma ${ }^{65}$ and $\mathrm{CSF}^{66}$ glutamate levels of 18 to 22 ALS patients were shown to be doubled compared to healthy controls and other neurological disorders patients. From then, the controversy continued, as some groups confirmed glutamate increases in plasma ${ }^{67}$ or $\mathrm{CSF}^{68}$ while others did not. ${ }^{69,70}$ Thereafter, claiming improvement in measurement techniques and in patient subclassification, several studies attempted to reconcile these divergent findings by highlighting that patients with spinal onset, but not bulbar onset, may possess higher glutamate levels in the $\mathrm{CSF}^{71}$ and/or plasma. ${ }^{72,73}$ Similarly, glutamate augmentations in serum were correlated to patients exhibiting severely progressive ALS versus patients with milder disease courses. ${ }^{74}$ Even if the most recent study published finds significant elevations of glutamate in ALS patients' CSF in absence of consistent correlations to clinical presentation or duration, ${ }^{75}$ overall, it appears reasonable to agree on the facts that: 1) glutamate elevation in patients' fluids is not a universal metabolic signature of ALS patients and hence a very unlikely factor to account for the induction of $\mathrm{MN}$ degeneration in ALS; 2) fluid glutamate increases are, however, a characteristic of a subset of ALS patients that needs to be further clarified to see if extracellular glutamate may be involved in modulating disease progression in these patients. Of interest, in the rodent models of ALS, the question of increased fluid glutamate levels was less investigated, or may be less reported due to negative results. In the SOD $1^{\mathrm{G} 93 \mathrm{~A}}$ mouse model, while one group has measured, by intracerebral microdialysis, a significant increase in glutamate in the cortical extracellular fluid, ${ }^{76}$ these findings could not be confirmed by a subsequent study, ${ }^{77}$ and another group found no difference in glutamate CSF and plasma levels among different stages of the disease, ${ }^{78}$ providing some closure to this question.

In theory, it is not so trivial to connect glutamate elevation in patients' fluids such as plasma, serum, or even CSF, to $\mathrm{MN}$ death. Relevant to this issue, even if, again, some divergent data have been published, ${ }^{79,80}$ it seems that the CSF of ALS patients is neurotoxic to cultured cortical neurons ( $\sim 40 \%$ decrease in survival),${ }^{81}$ to spinal MNs $(\sim 60 \%)$ and, to a lesser extent, to other spinal neurons $(\sim 15 \%) .{ }^{82}$ Although CSF glutamate levels have not been measured in these works, the authors have shown that the observed toxicity could be prevented by AMPA/KA GluR antagonists, but not by NMDA antagonists, supporting the involvement of excitotoxicity. In a third study that also does not report CSF glutamate concentrations, both AMPA blockade and metabotropic GluR class-I modulation showed some neuroprotective effect against ALS CSF toxicity. ${ }^{83}$ Intriguingly, the latter study reported that the addition of glutamate at concentrations that either mimic 
those found, on average, in ALS patients' CSF (ie, $5 \mu \mathrm{M}$ ), or 10 times higher (ie, $50 \mu \mathrm{M})$, did not recapitulate the reported ALS CSF neurotoxicity. Further, the authors showed that ALS CSF toxic activity is retained on a $5 \mathrm{kDa}$ filter and is not lost after a 15 minutes of boiling, suggesting that the neurotoxic factor(s) is a macromolecule resistant to heat and, by far, higher in molecular mass than glutamate (147.13 Da). In keeping with this, a very recent study demonstrates no correlation between glutamate concentrations in human patients' $\mathrm{CSF}$ and in vitro neurotoxic potency. ${ }^{75}$ Yet, in contrast to all of the previous studies, it was found that NMDA antagonists offer a complete rescue of cortical neuron survival whereas rescue is only partial with AMPA/KA antagonists. In summary, most of the studies point to the neurotoxicity of ALS patients' CSF, preferentially for $\mathrm{MNs}$, recently proven to be independent of CSF glutamate levels, and possibly, mediated by an unknown macromolecular toxic factor(s) inducing a neuronal death pathway mysteriously involving ionotropic GluRs at one point. This confirms that even if elevated glutamate is not the primary insult, other neurotoxic mechanisms may lead to a secondary excitotoxicity for which MNs appear the most vulnerable. Nonetheless, without the identification of the ALS CSF macromolecular toxic factor(s), it will be difficult to explore the relevance of these in vitro findings for the in vivo pathogenic process.

In contrast to investigations of ALS patients' fluids, several groups ${ }^{84-86}$ have found that glutamate levels in postmortem ALS patient tissues are consistently decreased, strongly supporting glutamate metabolism alterations in ALS. The analysis of the ALS patient ${ }^{87}$ and the mutant SOD1 ${ }^{\mathrm{G} 93 \mathrm{~A}}$ mouse ${ }^{88}$ by magnetic resonance spectroscopy revealed that, at early stages of the disease, brain glutamate content is elevated. The mouse study ${ }^{88}$ further demonstrates that this increase is region-specific (spinal cord $>$ medulla $>$ sensorimotor cortex, $0=$ cerebellum) and followed by a more extensive decrease at late stages of the disease, substantiating the results obtained in postmortem ALS patient tissues. Although consistent, so far the pertinence of these changes for the pathogenic processes remains murky.

\section{Environmental excitotoxins and ALS: fame, shame, and come-back}

Concomitant to the first report of increased glutamate levels in ALS patients' CSF, another early finding linking excitotoxicity to ALS had a groundbreaking impact in the field. Indeed, Spencer and colleagues showed that feeding monkeys with an environmental toxin ( $\beta$-methyl-amino-L-alanine, BMAA), whose consumption is thought to be responsible for the 100 times higher ALS incidence in the western Pacific island of Guam, was causing these animals to develop an ALS/Parkinson-like MN disorder. ${ }^{89}$ They described that the main features of neurodegeneration were in the motor cortex and ventral spinal cord and that the pathology could be alleviated by NMDA receptor antagonists. Subsequently, the hypothesis of BMAA being at the origins of Guam ALS was so widely challenged (eg, concentrations of BMAA in Guam ALS patients' brains and food that they consume are far below neurotoxic level; BMAA exhibits no consistent excitotoxic potency) that it had fallen into oblivion until a recent renewal of interest in the ALS community (for review $\mathrm{see}^{90-92}$ ). The main findings that made BMAA get back into the race are the demonstrations that: 1) it can be biomagnified in the food chain to reach neurotoxic levels; 2) human brains from ALS as well as from Alzheimer's and Parkinson's patients contain very high levels of protein-bound BMAA compared with controls, suggesting that the slow release of free BMAA from protein-bound reservoirs could last for years after remote exposures and explicate a chronic toxic effect; 3) BMAA becomes a potent excitotoxin only in the presence of bicarbonate, which is abundant in vivo. Still, recent evidence suggests that BMAA may be neurotoxic through several mechanisms other than excitotoxicity, such as inhibition of the $\mathrm{xc}^{-}$cystine-glutamate antiporter akin to oxidative glutamate toxicity ${ }^{93}$ and incorporation into proteins leading to protein misfolding or dysfunction. ${ }^{94}$ This hypothesis is particularly appealing in the context of ALS, knowing that accumulation of misfolded proteins in the ER leading to chronic ER stress is one of the major current theories to account for MN death in mutant SOD1 mouse models of familial ALS. ${ }^{95}$ If experimentally proven, BMAA-mediated protein misfolding and ER stress may provide evidence for the first common pathogenic process between familial and environment-linked sporadic ALS.

Other confirmed excitotoxins have been described as provoking MN disease-like syndromes following oral intake. For instance, the KA agonist domoic acid, biomagnified in mussels, was responsible for a food poisoning outbreak in Canada, leading initially to widespread neurologic dysfunction and later to chronic residual memory deficits and motor neuropathy or axonopathy. ${ }^{96,97}$ More specific to $\mathrm{MN}$ diseases, the chronic consumption of grass pea (Lathyrus sativus) causes lathyrism, an upper $\mathrm{MN}$ disorder primarily characterized by spastic disability of the lower extremities (for review see ${ }^{98}$ ). At the neuropathological level, cortical MNs with the longest axonal projections seem to exhibit a preferential vulnerability towards these compounds. It has 
been suggested that this may be due to their largest dendritic tree being covered by GluRs, potential targets for the liable grass pea excitotoxin $\beta$-N-oxalyl-L- $\alpha$, $\beta$-diaminopropionic $\operatorname{acid}(\beta-O D A P$ or BOAA). Indeed, $\beta$-ODAP is a potent AMPA receptor agonist ${ }^{99}$ which was shown to mimic several clinical features of lathyrism in monkeys following oral intake and to elicit $\mathrm{MN}$ death in rodent spinal cord following intrathecal injection. ${ }^{98}$ These observations strongly support the view that MNs may be peculiarly vulnerable to excitotoxicity and exogenous excitotoxins. However, even for lathyrism, which appears to be the most salient/consensual example, the efficacy of anti-excitotoxic therapeutic strategies has not been proven in animal models or in the human disease, which opens the possibility that, like for BMAA, other properties of $\beta$-ODAP may be at the roots of $\mathrm{MN}$ degeneration.

\section{Glutamate transport alterations in ALS: much ado about little}

The first explanation for increased glutamate levels in ALS patient fluids emerged when the efficiency of glutamate transport in ALS patient synaptosomes was found to be selectively decreased compared with control or other neurological disease patients. ${ }^{37}$ Further, this study showed that this transport defect was selective for glutamate and respected the regional specificity of the disease. This study finding, perfectly correlated to disease selectivity and specificity, started one of the most active controversies in the ALS literature. As glutamate transport implication in ALS was thoroughly and very impartially reviewed recently, ${ }^{100}$ we will limit our discussion to the most significant and most recent evidence necessary to reach a fair opinion on this subject.

High affinity glutamate or excitatory amino acid transporters (EAATs) refer to a protein family of 5 members (EAATs 1-5) using the $\mathrm{Na}^{+} / \mathrm{K}^{+}$transmembrane gradient to transport glutamate back into the cells following its synaptic release. ${ }^{101}$ While EAAT1 (GLAST in rodents) and EAAT2 (GLT-1 in rodents) are mainly located in astrocytes, EAAT3-5 are expressed by neurons throughout the brain. Among the EAATs, astrocytic EAAT2 has a primary role in maintaining extracellular glutamate at low levels compatible with both neurotransmission and neuronal survival. ${ }^{101,102}$ Indeed, astrocytes express much higher levels of EAAT2 than EAAT1 in vivo, and it has been demonstrated in genetic deletion studies that EAAT2 is responsible for $\sim 95 \%$ of total glutamate transport at the synapse. ${ }^{103}$ This gave a rationale for the avid study of EAAT2 dysfunction and expression defects to account for glutamate level alterations in ALS patients.

\section{EAAT2 loss accounts for reduced glutamate transport in ALS}

The first observation of decreased glutamate transport in ALS patients ${ }^{37}$ was confirmed and extended to the discovery of a selective and extensive loss of EAAT2 protein in the spinal cord and motor cortex of ALS patients. ${ }^{104,105}$ While these studies were pioneers in the field for studying the roles of glutamate transporter failure and noncell autonomous processes in ALS, they were all observations from a small number of patients, and the end-stage nature of the experimental material does not allow sorting out whether EAAT2 deficiency is a cause or a consequence of the disease process. Further, EAAT2 disappearance may not be ALS specific as this was reported for several other neurodegenerative and psychiatric diseases. ${ }^{101}$ Along this line, despite an isolated report that identified a polymorphism (N206S) altering EAAT2 function in sporadic ALS patients, ${ }^{106}$ and an exciting but later invalidated ${ }^{107}$ finding of EAAT2 mRNA selective splicing defect variants in ALS affected regions, ${ }^{108}$ no genetic linkage to the EAAT2 locus was detected and the extremely rare mutations of EAAT2 found in familial or sporadic patients do not give rise to transcript defects. ${ }^{109}$

Several groups also examined the function and levels of EAAT2/GLT-1 in the mutant SOD1 rodent model of ALS. In agreement with the human data, an early study demonstrated a $50 \%$ decrease in GLT- 1 protein in spinal cord extracts from end-stage SOD $1^{\mathrm{G} 85 \mathrm{R}}$ mice, ${ }^{33}$ while a second evidenced decreased glutamate uptake in synaptosomes extracted from end-stage SOD $1^{\mathrm{G} 93 \mathrm{~A}}$ mice. ${ }^{110}$ Then, addressing all of the shortcomings of these previous studies, Bendotti and collaborators demonstrated that the GLT-1 protein level reduction in SOD ${ }^{\mathrm{G} 93 \mathrm{~A}}$ mice was specific for affected regions, selective for GLT-1 over GLAST, not associated with GLT-1 mRNA decrease, and not significant in early-symptomatic stage where $\mathrm{MN}$ insult signs are already present versus end-stage. ${ }^{78}$ Altogether, these results indicate that GLT-1 decrease in SOD1 ${ }^{\mathrm{G} 93 \mathrm{~A}}$ mouse spinal cord may be due to post-transcriptional alterations of the protein and, importantly, is a very unlikely primary event leading to $\mathrm{MN}$ degeneration. Similar findings giving further credence to the same conclusion were reported in SOD1 ${ }^{\mathrm{G} 93 \mathrm{~A}}$ rats. ${ }^{111,112}$ At best, EAAT2/GLT1 decrease may be a contributor to disease progression in advanced stages but, knowing that astrocyte expression of glutamate transporters is dependent on neuron presence and activity in vitro ${ }^{113,114}$ and in vivo, ${ }^{115}$ we cannot exclude that it is MN dysfunction and/or loss that is eliciting GLT-1 expression downregulation. In keeping with this, it was recently proposed that kappa B-motif binding 
phosphoprotein (KBBP) regulates the activation of the GLT1/ EAAT2 promoter in astrocytes as a function of presynaptic neuronal activity. ${ }^{116}$ It was hypothesized that alteration/loss of presynaptic terminals during ALS disease process resulted in reduced astroglial KBBP expression and, ultimately, in transcriptional dysfunction of GLT-1.

\section{A secondary role for EAAT2 dysfunctions in ALS}

This notion of EAAT2 reduction playing a contributive, but not primary role, in $\mathrm{MN}$ degeneration in ALS is supported by several different approaches in vivo. The first strategy described, aimed at increasing EAAT2 protein through overexpression in ALS SOD1 ${ }^{\mathrm{G} 93 \mathrm{~A}}$ mice, showed that a doubled expression of EAAT2 increased glutamate uptake by 2-fold, delaying symptom onset (17\%) and MN death, without, however, noticeable effects on paralysis onset, weight decline or life span. ${ }^{117}$ Subsequently, several drugs, known to increase EAAT2 protein in astrocytes such as the $\beta$-lactame antibiotic ceftriaxone and the immunophilin ligand GPI-1046, were evidenced to both protect MN survival and to extend SOD1 ALS mouse lifespan (9\% and $12 \%$ respectively). ${ }^{118,119}$ Nevertheless, with these drugs having primarily multiple biological effects unrelated to EAAT2, we can assume that the modest improvement measured in ALS mice may be attributed to other unidentified mechanisms. To address the question from a reverse angle, Pardo et al crossed the SOD1 ${ }^{\mathrm{G} 93 \mathrm{~A}}$ mouse with a mouse heterozygous for GLT-1 ablation that displays a significant reduction in transporter protein. ${ }^{120}$ While, as expected, they observed an earlier and an exacerbated $\mathrm{MN}$ loss $(\sim 30 \%)$ in mice carrying both abnormalities, they did not detect an earlier motor onset, but an accelerated decline in motor strength, accompanied by only a very modest reduction in survival (4\%). Ultimately, we can conclude that these two complementary genetic studies argue for GLT-1 loss being somewhat associated with disease progression, but not a prime cause of $\mathrm{MN}$ degeneration.

Alternatively, it can be hypothesized that EAAT2 protein level reduction may be preceded by more discrete EAAT2 dysfunctions. These defects may be as crucial in terms of MN survival, may appear early and may be maintained long enough to pretend to play a key role in the ALS pathogenic process. Accordingly, it was established that oxidative stress results in the rapid inactivation of glutamate transporters in cultured astrocytes ${ }^{121,122}$ or when EAAT2 is co-expressed with human mutant but not wild-type SOD1 in Xenopus laevis oocytes. ${ }^{123}$ A cleavage by caspase-3 at a unique site located in the cytosolic C-terminal domain of EAAT2 was proposed to account for its oxidative stress-mediated inhibition. ${ }^{124}$ In contrast, a study found that transfection of both mutant G93A and wild-type SOD1 in primary astrocytes results in significant GLT-1 protein reduction independent of oxidative mechanisms. ${ }^{125}$ Dependent or not on oxidative stress, none of these studies made the link between GLT1/EAAT2 dysfunctions in astrocytes and MN death. Our group ${ }^{57}$ and others ${ }^{56,58}$ have evidenced that mutant SOD1-expressing astrocytes are selectively toxic to MNs in vitro. Yet, we further demonstrated that this death, while mediated by a soluble mechanism, was independent of glutamate alteration. ${ }^{57}$ Indeed, in our hands, primary astrocytes, prepared directly from rats or mice nontransgenic or transgenic for wild-type or different SOD1 mutations, exhibit no impairment in their capacity to clear excess extracellular glutamate. Further, we found similar extracellular glutamate levels in the different astrocyte culture genotypes, no decrease in GLT-1 protein content in association with SOD1 expression (unpublished data), and no protection of MNs from astrocyte toxicity with glutamatergic receptor antagonists. This suggests that, at least in vitro, astrocytes, produced directly from a relevant animal model of familial ALS, can be detrimental to MNs independent of glutamate transport dysfunction and associated excitotoxic mechanisms.

\section{EAAT2 is essential for the therapeutic replacement of ALS-diseased astrocytes}

Supporting the idea that, in ALS, MNs reside in a hostile astrocyte neighborhood, a recent study has reported that the focal replacement of astrocytes in cervical spinal cords of mutant SOD $1^{\mathrm{G} 93 \mathrm{~A}}$ rats through the transplantation of lineagerestricted astrocyte precursors, also called glial-restricted precursors (GRPs), had significant therapeutic effect. ${ }^{126}$ The transplanted GRPs differentiated efficiently into astrocytes in diseased tissue, reduced microgliosis, lessened MN loss $(\sim 15 \%)$, slowed motor declines $(\sim 5 \%)$ and extended animal survival $(\sim 10 \%)$ and disease duration ( $\sim 25 \%)$. Interestingly, GRPs genetically deficient in GLT-1 were unable to exhibit the same neuroprotective effect, but GRPs overexpressing GLT-1 did not improve the protection offered by nonengineered GRPs. Altogether, this indicates that astrocytes that do not express mutant SOD1 exert a positive GLT1dependent effect. However, rather than helping to cope with improbably increased extracellular glutamate levels (see previous discussion), this may mean that GLT-1 expression is essential for astrocytes to acquire neuronal supportive activities. For instance, glutamate capture into astrocytes is 
known to sustain antioxidant defenses through glutathione synthesis, ${ }^{127}$ and neuronal energy production through release of lactate. ${ }^{128}$

\section{Chronic glutamate transport alteration} is an unlikely culprit in MN degeneration

On the other hand, the chronic pharmacological alteration of glutamate transport in spinal cord organotypic cultures by treatment with competitive inhibitors was shown to produce a model of slow MN death, not strictly limited to MNs or to the ventral horn. ${ }^{129-131}$ However, in vivo, the same inhibitors of glutamate transport are well known to be inefficient in causing neuronal death despite the induction of massive increases in extracellular glutamate, stressing how glutamate itself may be innocuous compared with potent neurotoxic GluR agonists. ${ }^{132,133}$ It can be assumed that synaptic glutamate augmentations in combination with other underlying dysfunctions may be the key to triggering glutamate-associated neuronal death in vivo. These possibilities were tested, in the ALS context, by the group of Ricardo Tapia who first showed that, as in control mice, in end-stage mutant SOD $1^{\mathrm{G} 93 \mathrm{~A}}$ mice, a 2-hour perfusion of a competitive glutamate transport inhibitor caused a significant elevation in glutamate levels but no detectable associated neuronal damage, excluding collectively a potential exacerbated neuronal vulnerability to glutamate and a difference in glutamate transport capacity in these animals. ${ }^{77}$ Then, they demonstrated that a 10-day chronic infusion of the same inhibitor in the spinal cord of nontransgenic mice was likewise harmless to MNs. ${ }^{134}$ These two studies strongly support the view that glutamate transport deficiency is not a key factor in MN degeneration.

In conclusion, the numerous investigations on glutamate transporters in ALS have greatly increased our knowledge of the regulation of these transporters' expression and activity. Several lines of evidence point to the possibility that glutamate transport defects and the related excitotoxicity may play a role in the late stage of ALS disease progression. However, there are no consistent data to support defects in EAATs as having a primary role in the induction or the selectivity of MN degeneration taking place in ALS (see Figure 1 for summary).

\section{Motor neuron glutamate receptors in ALS: lost in translation}

Along with potential defects in extracellular glutamate levels and glutamate transport, GluR alterations have been exten-

\section{Astrocyte}

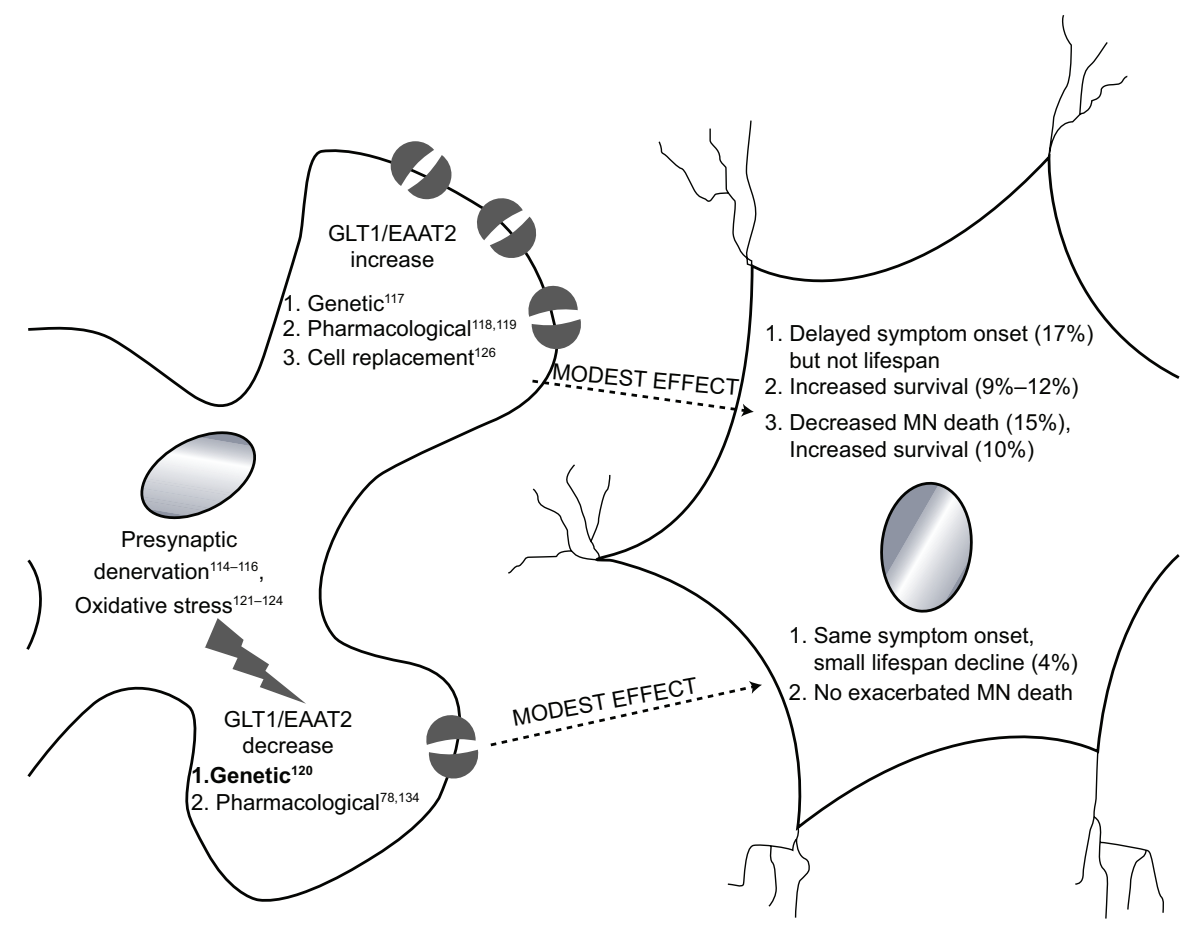

Figure I Modulating EAAT2/GLTI has only modest effect in amyotrophic lateral sclerosis mice.

Note: In order to evaluate the effect of glutamate transport modulation on SODI ${ }^{\text {G93A }}$ mice, EEAT2/GLTI expression was increased or decreased via different genetic or pharmacological approaches. None of these studies revealed a major effect on motor neuron (MN) survival or animal life span. 
sively investigated in ALS. It is consensually established that MNs have a high density of GluRs, express all their types, ${ }^{135-137}$ and are more vulnerable than other neuronal subsets to excitoxicity induced by influx of $\mathrm{Ca}^{2+}$ through GluRs. ${ }^{138-140}$ Most of the studies investigating the possible implication of GluRs in ALS pathogenesis are therefore particularly focused on ionotropic GluR NMDA and on GluR2 subunit expression and editing, which confer $\mathrm{Ca}^{2+}$ impermeability to the AMPA/KA GluR.

\section{Differential GluR expression and vulnerability to excitotoxicity in MNs}

Quantitative autoradiography studies of human tissues have determined that both NMDA and non-NMDA GluR are expressed in motor cortex, brainstem, and spinal cord with a particularly striking high density on lower MN somata. ${ }^{135,141-144}$ Intriguingly, further, MN groups classically described as resistant in ALS, such as the oculomotor nucleus, were shown to possess fewer NMDA binding sites and much denser AMPA binding sites in comparison to vulnerable MN groups, suggesting that higher NMDA GluR expression may account for the selective vulnerability of certain MNs in ALS. However, a plethora of evidence is more consistent with the hypothesis of the non-NMDA origin of the exacerbated MN vulnerability to EAAs. For instance, the single intrathecal injection of a high concentration of NMDA, contrary to AMPA agonists, had no effect on spinal MNs. ${ }^{145}$ Likewise, in a model of organotypic rat spinal cord culture and in vivo, larger MNs were shown to be relatively well preserved against NMDA exposure, ${ }^{146}$ but considerably more sensitive to AMPA/KA mediated toxicity. ${ }^{147-149}$ In addition, AMPA/KA receptor activation, through the continuous infusion of KA into the rat spinal subarachnoid space, induces a progressive and motor-selective behavioral deficit associated with a late loss of spinal MNs. ${ }^{150}$ Further, immunohistochemistry and in situ hybridization studies have emphasized that healthy human and rodent MNs express lower ${ }^{151-155}$ or even undetectable ${ }^{156,157}$ GluR2 subunit mRNA and protein, suggesting that $\mathrm{MN}$ AMPA/KA GluR have a higher permeability to $\mathrm{Ca}^{2+}$, which could account for $\mathrm{MN}$ hyper-susceptibility to excitotoxicity. The situation is slightly different in vitro, as in rat MN cultures ${ }^{158}$ and spinal cord tissues, ${ }^{159}$ GluR2-containing receptor clusters were found to be more abundant than GluR2-lacking clusters. However, the activation of micro-domains lacking GluR2 was suggested to be sufficient to greatly amplify $\mathrm{Ca}^{2+}$ influx locally and to participate in toxic mechanisms. ${ }^{158}$ In agreement, another in vitro study specified that short-term exposure to KA causes a selective MN death, completely dependent on extracellular $\mathrm{Ca}^{2+}$, insensitive to inhibitors of voltage-operated $\mathrm{Ca}^{2+}$ or $\mathrm{Na}^{+}$ channels, and fully inhibited by Joro spider toxin, a selective blocker of AMPA receptors lacking GluR2 subunit. ${ }^{140}$ In contrast, cortical neuron vulnerability to excitotoxicity is not correlated to GluR2-deficient AMPA/KA receptors, ${ }^{160}$ suggesting that $\mathrm{Ca}^{2+}$ influx through AMPA receptors may be especially important in $\mathrm{MN}$-associated excitotoxicity. Another interesting observation is that, rather than wholecell relative $\mathrm{Ca}^{2+}$ permeability of AMPA GluR, the AMPA current density, which is 2- to 3-fold higher in MNs than in other spinal neurons, may be sufficient to account for $\mathrm{MN}$ vulnerability to AMPA agonists. ${ }^{161,162}$

Of note, group I mGluRs were reported to have a dual role in excitotoxic-mediated $\mathrm{MN}$ degeneration, ${ }^{163}$ as some evidence supports their neuroprotective action ${ }^{164}$ against AMPA-mediated toxicity, ${ }^{165,166}$ whereas the greater expression of their subtype 1a in the vulnerable $\mathrm{MN}$ population in rat may exacerbate excitotoxic injury by increasing intracellular $\mathrm{Ca}^{2+}$ levels and activating PKC. ${ }^{167}$

\section{$\mathrm{Ca}^{2+}$-permeable AMPA GluR} are not the key to $\mathrm{MN}$ degeneration

To better understand the importance of AMPA GluR in MN vulnerability to EAAs, transgenic animal models targeting the AMPA GluR2 subunit were generated. Mice heterozygous for an editing incompetent GluR2 allele resulting in only $25 \%$ of $\mathrm{Ca}^{2+}$-impermeable AMPA GluR die prematurely from seizures and hippocampal pathology but are not associated with any ALS-like motor phenotype or motor neuron degeneration. ${ }^{168}$ In contrast, transgenic mice expressing a minigene for an artificial $\mathrm{Ca}^{2+}$-permeable GluR2 subunit are viable, but exhibit a late decline in motor function associated with neuronal death in the spinal cord and diverse other brain areas. ${ }^{169,170}$ As for knockout mice lacking the GluR2 subunit, they show only minor impairment in motor coordination even though the $\mathrm{Ca}^{2+}$ permeability of AMPA GluR was measured to be maximal in regions such as the hippocampus. ${ }^{171}$ The conflicting phenotypic consequences observed in these different models may be partially explained by the properties of AMPA receptor trafficking and subunit incorporation. The GluR2(Q) subunit is more readily targeted to the cell surface and incorporated into AMPA receptors than is an edited GluR2(R) subunit. ${ }^{172,173}$ We can therefore assume that, in the editingincompetent GluR2 mice, a higher density of $\mathrm{Ca}^{2+}$-permeable AMPA receptors will end up at the plasma membrane due to a more sustained assembly than in the two other models. This could ultimately lead to a greatly exacerbated vulnerability 
to excitotoxicity and explicate the premature death of these mice. More recently, mice were engineered for a cholinergic neuron-selective excision of some ADAR2 exons crucial for the enzyme activity, by using a vesicular acetylcholine transporter-Cre/LoxP system. ${ }^{174}$ These mice, referred to as AR2 mice, in which ADAR2 activity is ablated in 50\% of the $\mathrm{MNs}$, are relatively long lived ( $\sim 81$ weeks versus $\sim 105$ weeks for controls) and exhibit some motor abnormalities such as hypokinesis and decreased rotarod performance but no overt paralysis. Further, it was shown that the kinetics of the motor deficit in these mice was consistent with the degeneration of cells in the anterior horn of the spinal cord and that MNs known to be resistant in ALS such as those of the oculomotor nuclei are spared despite effective Cre/LoxP recombination. Taken together, these results indicate that GluR2-lacking or unedited GluR2-containing AMPA receptors, per se, cannot provoke severe paralytic disorders resembling ALS nor selective MN degeneration. Although the same MN subsets are observed to be more resistant to the ALS disease process and AMPA-mediated increased $\mathrm{Ca}^{2+}$ permeability, they may also be more resistant to any other insult.

\section{MN GluR alteration in ALS: zoom} in on GluR2 loss and editing defect

With all of these characteristics of MN GluR in mind, we may wonder whether GluRs are altered in ALS and play a key role in the pathogenic process. An opening argument for abnormal GluR permeability to $\mathrm{Ca}^{2+}$ in ALS is the observation of $\mathrm{Ca}^{2+}$ accumulation in MN terminals of ALS patients ${ }^{175}$ and in vacuoles of degenerating $\mathrm{MNs}$ in SOD1 ${ }^{\mathrm{G} 93 \mathrm{~A}}$ mice. ${ }^{176}$ In ALS patients, a specific reduction of NMDA receptor binding sites and NR-1 mRNA levels was observed in the ventral horn compared with control individuals, ${ }^{177,178}$ indicating that the $\mathrm{MNs}$ that were lost were expressing NMDA receptors. Reflecting earlier stages of the disease, a postsynaptic decrease of NR2A subunit expression was also recently reported in upper MNs of presymptomatic SOD $1^{\mathrm{G} 93 \mathrm{~A}}$ mice. ${ }^{179}$ Although these observations suggest that NMDA receptors could be involved in $\mathrm{MN}$ degeneration in ALS, intrathecal application of NMDA had no impact on MN survival in mice. ${ }^{145}$ In contrast, memantine, a noncompetitive NMDA receptor antagonist, significantly but quite modestly prolongs the survival of ALS mice $(\sim 7 \%)$ without affecting disease onset. ${ }^{180}$ However, because memantine is also a potent serotonin- $3^{180}$ and alpha7 nicotinic acetylcholine receptor ${ }^{181}$ antagonist and an agonist of dopamine D2 receptors, ${ }^{182}$ it is difficult to attribute its therapeutic effect to a selective action on NMDA receptors.
The contribution of AMPA receptors to the ALS disease process is more consistently supported by several studies. First, the survival of SOD $1^{\mathrm{G} 93 \mathrm{~A}}$ ALS rodents was prolonged by $\sim 10 \%$ after intraperitoneal injection of AMPA receptor antagonists. ${ }^{183,184}$ Then, crossbreeding SOD1 ${ }^{\mathrm{G} 93 \mathrm{~A}}$ mice with ChAT-GluR2 overexpressing mice, for which AMPA $\mathrm{Ca}^{2+}$-permeability is significantly reduced in cholinergic neurons, was shown to delay disease onset ( $19 \%)$ and mortality $(\sim 14 \%)$ and to alleviate SOD1 protein misfolding. ${ }^{185}$ In contrast, crossbreeding of SOD $1^{\mathrm{G} 93 \mathrm{~A}}$ mice with GluR2 knockout mice was found to accelerate disease progression and animal death ( $\sim 15 \%$ for both). ${ }^{186}$ As GluR2 mRNA levels are unchanged over the course of the disease in SOD $1^{\mathrm{G} 93 \mathrm{~A}}$ mice, ${ }^{187}$ but GluR2 protein is specifically decreased in spinal MNs before symptom onset, the beneficial effects of GluR2 overexpression may rely on both a global reduction in $\mathrm{Ca}^{2+}$ influx through AMPA GluR and on a compensatory GluR2 protein translation defect or instability. ${ }^{184}$ Nevertheless, no difference in GluR2 mRNA and protein expression was observed between human ALS and control tissues, ${ }^{155}$ or between resistant and vulnerable rat MNs. ${ }^{188}$ Altogether these results suggest that reduced expression of GluR2 is not a crucial factor predisposing MNs to degeneration in ALS per se but that AMPA GluRs have a modulatory role worth further investigation, at least, in the mutant SOD1-linked familial form of ALS.

Besides a decrease in GluR2 expression, a deficiency in GluR2 mRNA editing at the Q/R site also leading to increased $\mathrm{Ca}^{2+}$ permeability of AMPA GluR was observed in the ventral spinal gray matter of ALS patients (supposedly sporadic) and in single MNs compared with controls. ${ }^{189-191}$ This incomplete editing was region selective and was not observed in MNs from patients suffering from spinal and bulbar muscular atrophy or multiple system atrophy, suggesting that, although based on few human cases, this is specific to spinal MNs of ALS patients. In animal models crossing SOD $1^{\mathrm{G} 93 \mathrm{~A}}$ mice with GluR2(N) mice that express an unedited GluR2 subunit, progeny exhibited $a \sim 7 \%$ shorter lifespan ${ }^{169}$ and no GluR2 editing defect was found in symptomatic mutant SOD1 rats. ${ }^{192}$ No aberrant RNA editing was observed in the upper MN of ALS patients either, ${ }^{169}$ indicating that this is not associated with all MNs degenerating in ALS. This does suggest that GluR2 RNA editing anomalies may be a hallmark of some form of ALS (sporadic?) but not of SOD1-associated familial ALS. However, the direct involvement of GluR2 editing defect in sporadic ALS pathogenesis remains to be determined and is not supported by animal modeling of this defect, ${ }^{168,170}$ as discussed above. Knowing that oxidative or nitrosative stress 
taking place in ALS can result in abnormal RNA editing, impaired GluR2 editing could be the effect rather than the cause of ALS, and thus be a secondary contributor to MN degeneration. ${ }^{169} \mathrm{~A}$ single study has reported a higher proportion of flip versus flop variants of AMPA GluR subunits in spinal MN of ALS patients compared with control individuals, which suggests that the presence of slowly desensitizing AMPA receptors may also contribute to $\mathrm{MN}$ vulnerability in ALS. ${ }^{193}$ The significance of this alternative defect of AMPA GluRs remains enigmatic as it has not been confirmed or further investigated.

\section{Mutant SODI a potential catalyzer of $\mathrm{MN}$ vulnerability to excitotoxicity}

Microinjection of different SOD1 mutant cDNAs into rat primary neurons has been suggested to increase $\mathrm{MN}$ vulnerability to normally nontoxic glutamatergic stimulation via $\mathrm{Ca}^{2+}$ influx through AMPA receptors and subsequent SOD1 aggregation. ${ }^{194}$ These SOD1 aggregates are apparently forming selectively in MNs as they have not been observed in neurons resistant to ALS disease process. ${ }^{40}$ Other groups also found a peculiar sensitivity to excitotoxicity of MNs overexpressing mutant SOD $1{ }^{195,196}$ through AMPA/KA receptors, although others did not. ${ }^{197,198}$ Another study suggested that exacerbated excitotoxic death of SOD $1^{\mathrm{G} 93 \mathrm{~A}} \mathrm{MNs}$ may not result directly from a greater $\mathrm{Ca}^{2+}$ influx through AMPA receptors but from voltage-dependent $\mathrm{Ca}^{2+}$ channels activated secondary to an abnormally increased AMPA-mediated depolarizing current. ${ }^{199}$ Several differences in cell culture conditions or in mutant SOD1 overexpressing strategies may account for these discrepancies. Although there is unfortunately no direct in vivo evidence to reach a definite verdict in this case, most studies support mutant SOD1 expression as a sensitizing factor in excitotoxicity.

\section{Astrocytes: a new piece in the excitotoxic puzzle in ALS}

A very original study uncovered that spinal astrocytes from two rat strains are differently regulating GluR2 expression and their associated $\mathrm{Ca}^{2+}$ permeability in $\mathrm{MNs}$, thereby influencing their vulnerability to excitotoxicity. ${ }^{198}$ Importantly, astrocytes expressing mutant SOD1 lose their capacity to upregulate GluR2 expression in MNs, which could participate in the mechanisms leading to $\mathrm{MN}$ degeneration in ALS. Furthermore, the growth factor vascular endothelial growth factor, which is secreted by astrocytes and which stimulates GluR2 expression in MN in vivo and in vitro, ${ }^{200}$ was found to prolong survival of ALS mice by $\sim 18 \%$ to
$30 \%{ }^{201,202}$ Besides, a strong upregulation of mGluR5 mRNA and protein expression was observed in spinal astrocytes of ALS patients ${ }^{203}$ and mutant SOD1 transgenic animals ${ }^{204}$ compared with controls. This GluR5 increase was suggested to contribute to the astrocytosis observed in ALS and to constitute a "failed attempt" to stimulate astrocyte glutamate uptake, as mGluR5-mediated enhancement of glutamate transport is deficient in astrocytes derived from mutant SOD1 rats. ${ }^{205}$

\section{Other putative players in the excitotoxic deadly game in ALS}

Chloride influx via voltage-dependent channels is known to worsen AMPA GluR-mediated MN death through a partial repolarization that amplifies AMPA receptor conductance and toxic elevation in $\mathrm{Ca}^{2+}$ influx. ${ }^{206} \mathrm{Co}$-administration of GABA with EAAs further enhanced this $\mathrm{Cl}^{-}$influx and resulting cell death. This phenomenon could be particularly relevant to MNs that present a high density of AMPA receptors coupled to an important GABAergic innervation. ${ }^{207}$

Because $\mathrm{Ca}^{2+}$ can also enter the cells via voltagesensitive $\mathrm{Ca}^{2+}$ channels activated by cell membrane depolarization, ${ }^{208}$ the intrinsic $\mathrm{MN}$ excitability properties may play a major role in the ALS $\mathrm{Ca}^{2+}$-mediated excitotoxicity. Altered electrophysiologic axonal properties such as persistent sodium and/or potassium channel conductance were actually found in ALS patients ${ }^{209,210}$ and might explain the ectopic firing of motor units and the axonal hyperexcitability observed in presymptomatic and symptomatic patients. These abnormalities responsible for fasciculations are heterogenic and not always detected in mutant SOD1 animal models. . $^{21,212}$

D-serine, a physiological co-agonist of the NMDA receptor, was suggested to amplify ALS MN excitability by increasing the receptor's affinity for glutamate, ${ }^{213,214}$ even though the expression of NMDA receptors is kept low in this disease. ${ }^{142,177}$ An increase of D-serine was observed in spinal cords of mutant SOD1 mice and in familial and sporadic ALS patients. ${ }^{215}$ Further, primary spinal cord neurons from ALS mice were shown to be more vulnerable to NMDA toxicity in a D-serine-dependent manner than those from control mice, and removal of endogenous D-serine from spinal cord cultures of SOD1 mice attenuated NMDA receptor-mediated $\mathrm{MN}$ death. ${ }^{215}$

Finally, several mechanisms related to mitochondrial dysfunction, such as oxidative stress and energy depletion, described to take place in ALS disease process, may make MNs vulnerable to "slow onset" or "secondary excitotoxicity" 
(for review see ${ }^{216}$ ). These various insults can lead to the loss of membrane potential which, in turn, may release the $\mathrm{Mg}^{2+}$ blockade from NMDA receptors and permit excess $\mathrm{Ca}^{2+}$ entry into neurons. Under these conditions, levels of glutamate observed in normal neurotransmission may damage already diseased MNs.

In conclusion, data generated from several in vitro and in vivo studies suggest that alteration in GluR properties may be a secondary contributing factor but not a primary element accounting for the selective MN death in ALS (for summary see Figure 2).

\section{Calcium: the crossroad of $\mathrm{MN}$ termination}

$\mathrm{Ca}^{2+}$ is the most abundant metal by mass in many animals, of which $99 \%$ participates in the mineralization of the bones and only $1 \%$ serves a myriad of critical biological functions. Most of these physiological functions are regulated in neurons and astrocytes by transient variations of intracellular $\mathrm{Ca}^{2+}$ concentrations $\left(\mathrm{Ca}^{2+} \mathrm{i}\right)$ via complexes exchanges across the plasma, mitochondrial and ER membranes, and interplays with $\mathrm{Ca}^{2+}$ buffering proteins. ${ }^{217}$ When $\mathrm{Ca}^{2+}$ load exceeds the capacity of regulation of the cell, $\mathrm{Ca}^{2+}$-dependent toxic pathways may be activated. Due to its crucial importance in brain functioning as both a second messenger and a cell death mediator, alterations in $\mathrm{Ca}^{2+}$ homeostasis have been suggested to be implicated in the onset/progression of various neurodegenerative diseases, such as Parkinson's, Alzheimer's, and Huntington's (for reviews $\operatorname{see}^{218,219}$ ).

\section{$\mathrm{Ca}^{2+}$ and excitotoxicity: the never-ending story}

Twenty-three years ago, using mature cortical neuronal cultures, Choi ${ }^{15}$ was the first to demonstrate that a low glutamate exposure mediated a delayed $\mathrm{Ca}^{2+}$ influx via NMDA receptors leading to a gradual neuronal disintegration. As discussed in

\begin{tabular}{|c|c|c|}
\hline & PRO & CON \\
\hline $\begin{array}{l}\text { AMPA } \\
\text { implication } \\
\text { in ALS } \\
\text { pathogenic } \\
\text { process }\end{array}$ & 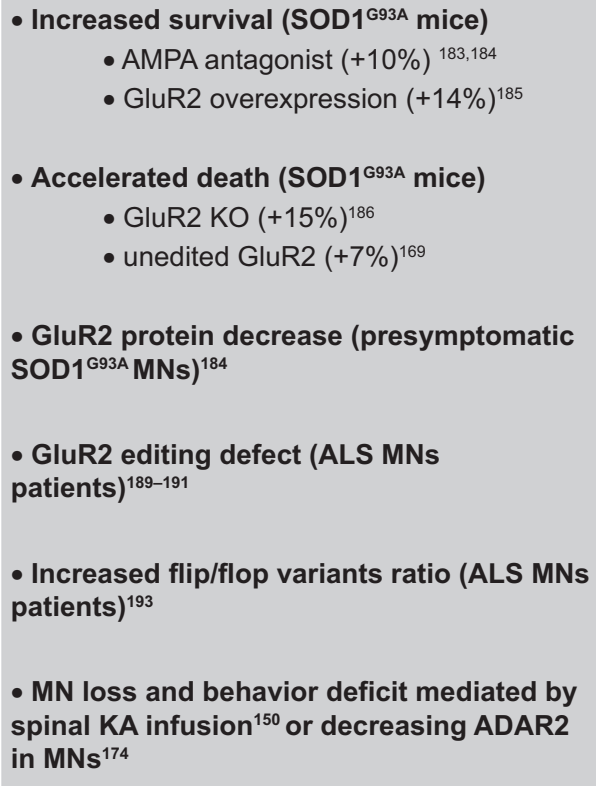 & $\begin{array}{l}\text { - No GluR2 mRNA/protein levels difference } \\
\text { in: } \\
\text { - MNs of ALS and control patients }{ }^{155} \\
\text { - ALS resistant and vulnerable MNs }{ }^{188} \\
\text { - No GluR2 editing defect in: } \\
\text { rats }{ }^{192} \\
\text { - upper MNs of ALS patients }{ }^{191} \\
\text { - Weakness of all the pro-arguments that are } \\
\text { related to modest effects }\end{array}$ \\
\hline $\begin{array}{l}\text { NMDA } \\
\text { implication } \\
\text { in ALS } \\
\text { pathogenic } \\
\text { process }\end{array}$ & $\begin{array}{l}\text { - Increased survival but no delayed disease } \\
\text { onset with NMDA antagonist (SOD1 } 1^{\mathrm{G} 93 \mathrm{~A}} \\
7 \%)^{180} \\
\text { - Decreased NMDA binding site density } \\
\text { (upper MNs of presymptomatic SOD1 } \\
\text { mice and ALS patient ventral horn })^{177-179}\end{array}$ & $\begin{array}{l}\text { - Ventral horn MNs resistant to NMDA } \\
\text { exposure }^{145} \\
\text { - Weakness of the few pro-arguments that } \\
\text { are related to modest effects }\end{array}$ \\
\hline
\end{tabular}

Figure 2 Evidence in favor or against the involvement of AMPA/KA and NMDA receptors in amyotrophic lateral sclerosis (ALS) pathogenic process.

Note: Many arguments support a limited but actual involvement of AMPA/KA receptors in amyotrophic ALS. Considering the weakness of all the pro-arguments, AMPA receptor defects are more likely implicated in late stage of disease progression rather than in its initiation (a). The involvement of NMDA being even less supported, its role may be further minor in ALS pathology (b).

Abbreviations: $\mathrm{MN}$, motor neuron; KA, kainate. 
the previous sections, initially, $\mathrm{Ca}^{2+}$ entered the ALS pathogenic cascade via its possible increased influx in $\mathrm{MNs}$ through altered $\mathrm{Ca}^{2+}$-permeable GluR leading ultimately to $\mathrm{MN}$ excitotoxic death. ${ }^{220}$ Interestingly, later, it was suggested that the chief determinant of glutamate-mediated $\mathrm{Ca}^{2+}$ neurotoxicity is not really the amount of $\mathrm{Ca}^{2+} \mathrm{i}$ but the path and duration of the $\mathrm{Ca}^{2+}$ increase. For instance, it was suggested that focal increases in $\mathrm{Ca}^{2+}$ in the vicinity of GluR could be coupled to downstream neurotoxic second messengers via interactions with regionspecific adaptor proteins and enzymes. ${ }^{221,222}$ In cultures of mouse spinal and cortical neurons, it was demonstrated that the neurotoxicity induced by long-duration/low-level glutamate exposure was primarily triggered by $\mathrm{Ca}^{2+}$ influx through NMDA receptor channels, although the same $\mathrm{Ca}^{2+}$ load was mediated by NMDA, AMPA/KA, and other $\mathrm{Ca}^{2+}$-permeable channels. ${ }^{221,222} \mathrm{~A}$ similar study further demonstrated that this chronic/low glutamate exposure selectivity triggers MN death in spinal neuronal cultures in contrast to acute/high-dose glutamate exposure which is nonspecifically toxic. ${ }^{223}$ Over the course of chronic/low glutamate exposure, spinal neurons first experience a transient increase in $\mathrm{Ca}^{2+} \mathrm{i}$, followed by a sustained and irreversible $\mathrm{Ca}^{2+} \mathrm{i}$ rise, indicating imminent cell death due to the loss of $\mathrm{Ca}^{2+}$ homeostasis maintenance capacity. ${ }^{221}$ Altogether, these observations are particularly relevant to both sporadic and familial ALS, knowing that $\mathrm{Ca}^{2+}$ accumulation was observed in MN terminals of sporadic ALS patients, ${ }^{175}$ and that an early $\mathrm{Ca}^{2+} \mathrm{i}$ increase was also reported in vulnerable spinal MNs of SOD1 ${ }^{\mathrm{G} 93 \mathrm{~A}}$ mice. ${ }^{176}$ Further, an explanation for increased $\mathrm{Ca}^{2+}$ in $\mathrm{MNs}$ is offered despite the lack of consistent evidence for increased glutamate levels in ALS patients or animal models.

One of the most consensually admitted hypotheses to explain the $\mathrm{Ca}^{2+}$ accumulation observed in ALS is that MN $\mathrm{Ca}^{2+}$ buffering capacity is impaired. Indeed, the way MNs handle $\mathrm{Ca}^{2+}$ overload during excitatory neurotransmission is a likely candidate for their peculiar fragility. Supporting this view, the amplitude of the $\mathrm{Ca}^{2+}$ signal in response to AMPA receptor or voltage-dependent $\mathrm{Ca}^{2+}$ channel activation was not significantly different between controls and $\mathrm{SOD} 1^{\mathrm{G} 93 \mathrm{~A}} \mathrm{MNs}$, but the time for $\mathrm{Ca}^{2+} \mathrm{i}$ recovery to basal level was significantly slower in mutant MNs after AMPA, but not voltage-dependent $\mathrm{Ca}^{2+}$ channel activation. ${ }^{224}$ Interestingly, the same defect was not observed in SOD $1^{\mathrm{G} 93 \mathrm{~A}}$ cortical neurons. These findings suggest that it is the capacity of $\mathrm{Ca}^{2+} \mathrm{i}$ clearance following its entry through AMPA GluR which is specifically altered in ALS MNs. There is also evidence showing that vulnerable MNs, lost early in human or rodent ALS, are deficient in the
$\mathrm{Ca}^{2+}$-binding proteins calbindin-D28K and parvalbumin, whereas MNs damaged later or relatively spared, express high levels of these $\mathrm{Ca}^{2+}$-buffering proteins. ${ }^{176,225}$ Transgenic mice overexpressing parvalbumin in spinal MNs were interbred with mutant SOD1 mice and exhibited a $\sim 17 \%$ delayed onset of motor defects and an $\sim 11 \%$ prolonged survival. ${ }^{226}$ However, the marginal survival extension in this double transgenic mouse implies that other mechanisms associated or not with intracellular $\mathrm{Ca}^{2+}$ are taking place in ALS pathogenesis.

\section{Mitochondria and ER under stress}

Of note, $\mathrm{MN}$ structures and synaptic function tightly dependent on $\mathrm{Ca}^{2+}$ levels are reported to be impaired in ALS. In fact, observations of ER and mitochondrial abnormalities and $\mathrm{Ca}^{2+}$ dysfunction have been extensively documented in MNs of sporadic ALS patients and in ALS mouse models (for review see $\left.{ }^{220}\right)$. Although several pathways may be involved in the $\mathrm{Ca}^{2+} \mathrm{i}$ augmentation observed in ALS, increased $\mathrm{Ca}^{2+}$ permeability through GluR is very attractive in the sense that this has been shown to induce organelle-specific dysregulation in neurons. It is, however, impossible to determine, as for the chicken-and-egg mystery, which came first: the increase in $\mathrm{Ca}^{2+} \mathrm{i}$ or the organelle impairment.

Under physiological conditions, mitochondrial uptake represents a major clearance mechanism for glutamate-induced $\mathrm{Ca}^{2+}$ loads in neurons. ${ }^{227}$ Interestingly, a brief exposure to AMPA/KA triggers substantial mitochondrial $\mathrm{Ca}^{2+}$ loading in MNs but not in ALS-resistant GABAergic interneurons, although both neuronal populations express a large number of $\mathrm{Ca}^{2+}$ permeable AMPA/KA receptors and present a significant cytosolic $\mathrm{Ca}^{2+}$ increase. ${ }^{139,228}$ Remarkably, MNs were reported to exhibit a lower mitochondrial density per volume compared with other neuronal subsets, which could contributed to their higher vulnerability to $\mathrm{Ca}^{2+}$ overloads. ${ }^{229}$ Consistent with this, $\mathrm{MN}$ mitochondrial $\mathrm{Ca}^{2+}$ overload was reported even after brief glutamate/NMDA stimulation. ${ }^{223}$ Further, repetitive short KA stimulations induce, specifically in MNs, a gradual increase in peak and baseline $\mathrm{Ca}^{2+} \mathrm{i}$ due to the saturation of mitochondrial buffering capacity. ${ }^{229}$ These findings confirm that MNs are particularly susceptible to mitochondrial $\mathrm{Ca}^{2+}$ overload and provide an explanation for the chronic mitochondrial $\mathrm{Ca}^{2+}$ overload reported in nerve terminals of ALS patients $^{175}$ and for the significant decrease in mitochondrial $\mathrm{Ca}^{2+}$ uptake observed in brain and spinal cord of SOD ${ }^{\mathrm{G} 93 \mathrm{~A}}$ mice. ${ }^{230}$ Mitochondrial $\mathrm{Ca}^{2+}$ overload may induce swelling, membrane potential depolarization, and finally opening of the permeability transition pore. It results in dissipation of mem- 
brane potential, loss of ATP synthesis and ion homeostasis, and finally release of pro-apoptotic proteins (for review $\left.\mathrm{see}^{44}\right)$. Although the mechanisms leading to mitochondrial alteration are not clear, it is suggested that mitochondria may be damaged by their own increase in reactive oxygen species (ROS) production subsequent to GluR overstimulation and $\mathrm{Ca}^{2+}$ overload. ${ }^{223}$ In MNs, excitotoxicity-mediated ROS was described as creating a vicious circle, since after freely crossing neuronal membranes, they can inflict damage to astrocytes notably through oxidation and disruption of glutamate transporters, thereby exacerbating the overstimulation of MN GluR. ${ }^{231}$ Alternatively, elevated $\mathrm{Ca}^{2+} \mathrm{i}$ was shown to promote unusual aggregation of mutant SOD1 inside of mitochondria, thereby worsening the organelle's dysfunction. ${ }^{232}$ On the other hand, it was shown, in rat spinal cord cultures, that mitochondrial dysfunction induced by the respiratory chain inhibitors rotenone and malonate causes activation of non-NMDA and/or NMDA GluR resulting in a selective MN death. ${ }^{233}$ This suggests that mitochondrial dysfunction and excitotoxicity may predispose $\mathrm{MNs}$ to each other and are tightly interrelated mechanisms. Since the rotenone- or malonate-induced $\mathrm{MN}$ death was blocked by glutamatergic receptor antagonists in absence of glutamate concentration elevation in the media, the authors hypothesized that these respiratory chain inhibitors may affect a portion of the membrane-incorporated GluR2 subunits or interfere with GluR2 mRNA editing. In agreement, in cortical upper MN explants, chronic mitochondrial inhibition with malonate results in MN death by excitotoxicity via both NMDA and non-NMDA receptors. ${ }^{234}$

Mitochondria exchanges $\mathrm{Ca}^{2+}$ with the ER to synchronize physiological functions. ER is another $\mathrm{Ca}^{2+}$ intracellular store that regulates $\mathrm{Ca}^{2+}$ homeostasis by taking up the ions through $\mathrm{Na}^{+} / \mathrm{Ca}^{2+}$ exchanger or by fast releasing it after $\mathrm{Ca}^{2+}$-induced ryanodine receptors (RyR) or inositol triphosphate receptors (IP3R) activation. ${ }^{235}$

Although a plethora of evidence suggests that ALS is associated with ER stress and dysfunction, ${ }^{236}$ only a few studies imply that glutamate-mediated $\mathrm{Ca}^{2+}$ influx may impact ER functions in MNs. Among the few insights, it was shown that $\mathrm{Ca}^{2+}$ entry through AMPA receptors caused RyR-mediated $\mathrm{Ca}^{2+}$-induced $\mathrm{Ca}^{2+}$ release from the ER in MNs. ${ }^{220,237}$ Because some subtypes of RyR are only present in MNs, they may specifically amplify $\mathrm{Ca}^{2+} \mathrm{i}$ level in MNs after GluR activation. ${ }^{238}$ Along the same line, inhibition of ER-Ca ${ }^{2+}$ release with RyR and IP3R inhibitors was demonstrated to reduce cytosolic $\mathrm{Ca}^{2+}$ increase, mitochondrial damage, and excitotoxicity after NMDA stimulation in cultured cortical neurons and in organotypic slices. ${ }^{239}$ Unfortunately, none of these studies has yet been confirmed or reproduced in an ALS context such as in SOD1 mutant animals.

If the reuptake of $\mathrm{Ca}^{2+}$ by mitochondria and ER is important in the glutamate-mediated toxic cascade, some evidence support that $\mathrm{Ca}^{2+}$ release from these organelles is equally crucial. Indeed, glutamate excitotoxicity was shown to be alleviated by blocking $\mathrm{Ca}^{2+}$ release from intracellular stores with dandrolene. ${ }^{240}$

In conclusion (see Figure 3 for summary), accumulating data suggest that, in ALS, MNs cannot handle large activityinduced $\mathrm{Ca}^{2+}$ load originating from $\mathrm{Ca}^{2+}$-permeable GluR. However, abnormally high intracellar $\mathrm{Ca}^{2+}$ may also arise, in MNs, from defective buffering capacities due to impaired mitochondria and ER reuptake, or low endogenous $\mathrm{Ca}^{2+}$ binding protein content. In ALS, $\mathrm{Ca}^{2+}$ homeostasis alteration may be at the center of a vicious circle between mitochondria, $\mathrm{ER}$, and plasma membrane GluR precipitating $\mathrm{MN}$ death. If we consider how early mitochondria and ER alterations are described in ALS compared with glutamate-associated alterations, we can assume that mitochondrial and ER dysfunctions are unfortunate converging points of multiple dysfunctional pathways in the disease pathogenesis, but probably not the specific consequence of increased $\mathrm{Ca}^{2+} \mathrm{i}$ after GluR activation.

\section{Conclusion and glutamate- associated therapeutic perspectives in ALS}

Based on the accumulation of evidence associating glutamate pathway alteration in ALS, we must perforce recognize that there is certainly no smoke without fire. But at which level and to what extent is glutamate crucial in the ALS disease process? The current consensus is that CSF glutamate levels are increased in $40 \%$ of sporadic ALS patients ${ }^{71}$ and thus do not represent an universal metabolic signature for ALS. Further, the biological significance of this glutamate increase remains undetermined, as the toxicity of ALS patient CSF is independent of glutamate levels but is incongruously dependent on GluR. ${ }^{75,83}$ Then, if the discovery of environmental EAAs predisposing to ALS or ALS-like syndrome, such as BMAA, gave a serious impetus to the investigation of excitotoxicity in ALS research, the most recent hypotheses on the origin of BMAA chronic toxicity are rather oriented toward its pathological incorporation into proteins and associated protein misfolding/ aggregation/dysfunction. ${ }^{94}$ Regarding glutamate transport and, in particular, EAAT2/GLT1 defects, it appears reasonable to agree with the fact it represents a secondary mechanism in ALS, ${ }^{78,241}$ maybe just circumstantial to neurodegeneration, ${ }^{116}$ 


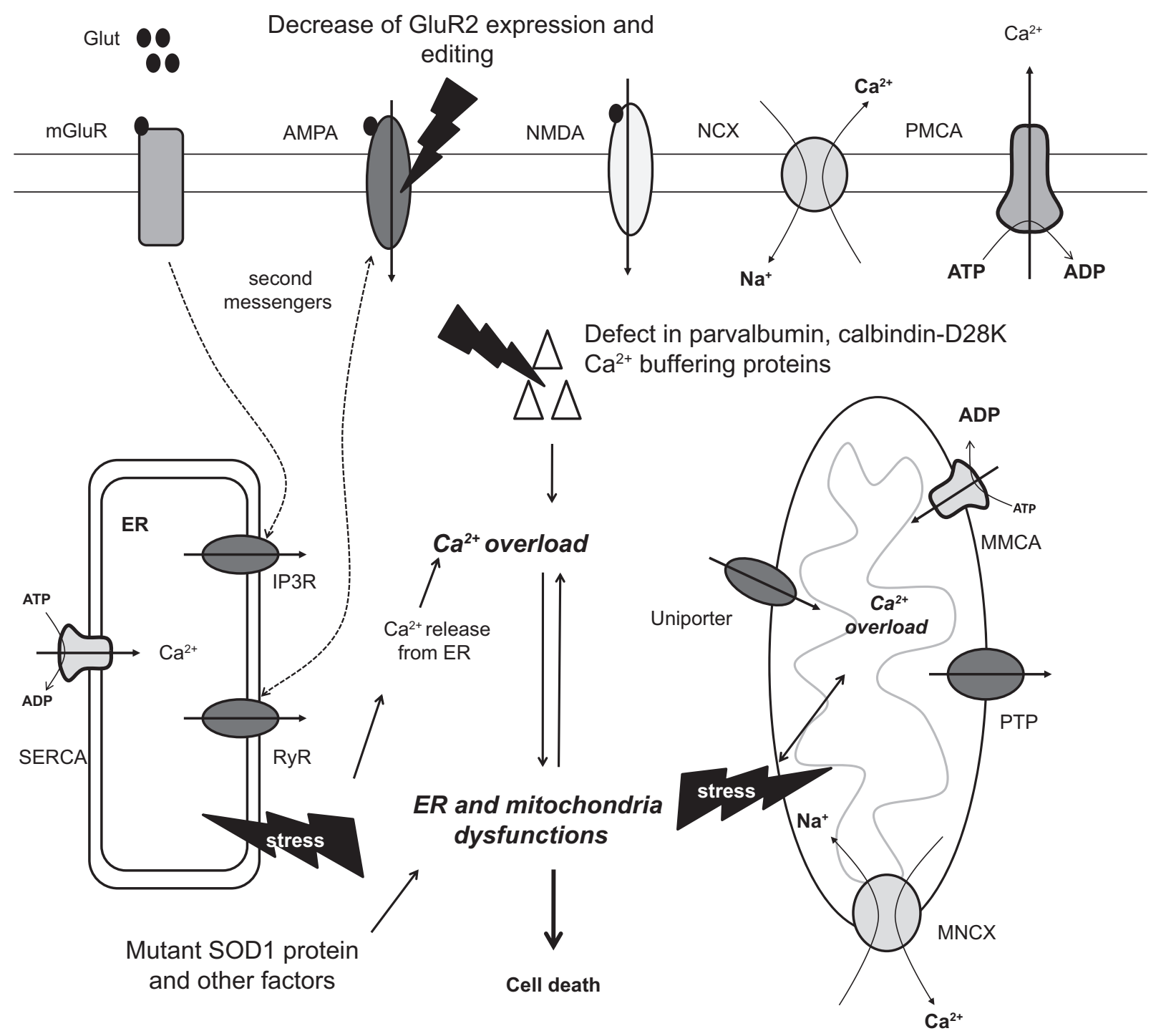

Figure 3 Converging pathological pathways leading to $\mathrm{Ca}^{2+}$ overload in amyotrophic lateral sclerosis (ALS) motor neurons (MNs).

Note: In ALS, glutamate initiates several mechanisms that can participate to $\mathrm{Ca}^{2+i}$ overload and ultimately motor neuronal death. First, the cell specific decrease of GluR2 subunit expression and editing defect may exacerbate $\mathrm{Ca}^{2+}$ permeability of AMPA receptors. Intracellular $\mathrm{Ca}^{2+}$ release may also originate from endoplasmic reticulum (ER) after indirect activation of IP3R and RyR by GluRs or from mitochondria through MNCX. The $\mathrm{Ca}^{2+} \mathrm{i}$ concentration is then normally regulated by mitochondrial (MMCA, uniporter) and ER (SERCA) uptake, plasma membrane extrusion (NCX, PMCA) and by $\mathrm{Ca}^{2+}$ binding protein buffering. In ALS, ER, and mitochondrial Ca ${ }^{2+}$ buffering capacities may be impaired by ongoing stress. Besides reduced buffering capacity due to low level of $\mathrm{Ca}^{2+}$-binding proteins in $\mathrm{ALS}$ vulnerable MNs, evidence has been provided for mitochondrial $\mathrm{Ca}^{2+}$ overload. This can result in the opening of the PTP leading to membrane potential dissipation, ATP synthesis loss, and pro-apoptotic proteins release.

Abbreviations: IP3R, inositol-I, 4, 5-trisphosphate receptor; RyR, ryanodine receptor; PMCA, plasma membrane Ca ${ }^{2+}$ pump; NCX, Na ${ }^{+} / \mathrm{a}^{2+}$ exchanger; SERCA, sarcoendoplasmic reticulum $\mathrm{Ca}^{2+}$ ATPase; MNCX, mitochondrial $\mathrm{Na}^{+} / \mathrm{Ca}^{2+}$ exchanger; PTP, permeability transition pore; MMCA, mitochondrial membrane Ca ${ }^{2+}$ ATPase.

although it could participate in the late stage of disease progression. As for GluR receptor deficiency in ALS, most of the evidence points to a modest but preponderant role of GluR2, especially in mutant SOD1-linked familial ALS, in the late modulation but not the induction of the disease process. ${ }^{183-185,187,188}$ Finally, if ALS MN incapacity to handle large activity-induced $\mathrm{Ca}^{2+}$ load appears solid, ${ }^{175,176}$ the origin of calcium overload in ALS is more uncertain. Abnormally high influx through $\mathrm{Ca}^{2+}$-permeable GluR, impaired mitochondria and ER buffering, and low endogenous $\mathrm{Ca}^{2+}$ binding protein content may all contribute to cytosolic $\mathrm{Ca}^{2+}$ accumulation. Nevertheless, knowing that mitochondrial and ER alterations are now described as the earliest detectable alterations in ALS pathogenesis (for review see ${ }^{95,242}$ ), their role may be preponderant compared to glutamate-associated $\mathrm{Ca}^{2+}$ alteration that may arise at a later stage.

Now, how can we translate these different glutamate-associated alterations into realistic therapeutic perspectives for ALS? First of all, we must acknowledge that the unique currently available Food and Drug Administra- 
tion-approved treatment for ALS, riluzole, which prolongs patient survival by only few months, is defined as a general inhibitor of glutamatergic transmission. ${ }^{243,244}$ Notably, riluzole inhibits voltage-dependent $\mathrm{Na}^{+}$channels by stabilizing their inactivate state. ${ }^{245}$ Riluzole was also reported to enhance glutamate transport, ${ }^{12,246}$ to inhibit glutamate release, and to prevent activation of the intracellular signaling pathway associated with GluR. ${ }^{247}$ Despite this supposedly multilevel effect on glutamatergic transmission, riluzole efficacy is in reality very modest, which suggests that the hyperexcitability associated with glutamate or excitotoxicity may have an equally modest role in ALS pathogenesis. In agreement, in ALS SOD1 mice, riluzole did not modify disease onset and only humbly extended animal survival (11\%), an effect comparable to the one observed in sporadic ALS patients. ${ }^{248}$ Nevertheless, with most of the effects of riluzole being indirect, one can argue that more specifically targeted drugs or a combination of these could exhibit a greater therapeutic effect. When we review the previous drug-based therapeutic strategies targeting glutamate-mediated excitotoxicity in mice (AMPA antagonist, ${ }^{183}$ EAAT2 upregulation, ${ }^{118,119}$ and caboxypeptidase II inhibition), ${ }^{249}$ none was found to consistently modify disease onset and all only modestly extended animal life span $(6 \%-15 \%)$. In human clinical trials, treatment with the AMPA/KA antagonist topiramate worsened the patient's condition as it accelerated loss of muscle strength and elicited a series of adverse effects. ${ }^{250}$ Clinical trials with the NMDA antagonists dextromethorphan or memantine (acting on other non-GluR; see GluR section) did not elicit any adverse effect or beneficial effect on motor decline, patient vitality, life quality, ${ }^{251}$ or survival; ${ }^{252}$ the results on life expectancy are in the process of being collected for the newest study. ${ }^{251}$ Similarly, inhibitors of glutamate release, such as lamotrigine, were inefficient in improving human ALS. ${ }^{253}$ The only positive outcome, other than for riluzole, ever reported for antiglutamatergic drug concerns the treatment of ALS patients with the glutamatergic modulator gabapentin; ${ }^{254}$ however this finding was later invalidated. ${ }^{255}$ Some have suggested that targeting glutamate transport may be a safer and more efficient strategy than targeting glutamate receptors due to the vast adverse effects of their inhibitors, which waits to be demonstrated. ${ }^{256}$

Altogether, these different clinical trials are not very encouraging for antiexcitotoxic-based ALS therapy. Nevertheless, the strategies targeting oxidative stress, inflammation, or energetic metabolism were no more successful (for review see $^{257}$ ). So far, all of the mechanisms that have been targeted are very general cell death mechanisms involved in the final progression rather than in the initiation of the disease. The discovery of a really efficient ALS therapy will probably arise only when the earliest pathogenic mechanisms leading to $\mathrm{MN}$ dysfunction and death have been unraveled. In the meantime, the best hope for halting ALS propagation certainly relies on the development of multidrug therapies targeting several pathogenic mechanisms that converge on dysfunctions that overwhelm the MNs such as calcium overload.

\section{Acknowledgments}

The authors wish to thank Dr. V Jackson-Lewis for her comments, advice, and assistance in preparing this manuscript. This study is supported by Muscular Dystrophy Association/ Wings-over-Wall Street, US National Institutes of Health NS042269, NS062180, NS064191, NS38370, NS11766, AG 21617 and NS062055, US Department of Defense Grant DAMD 17-03-1, W81XWH-08-1-0522, and W81XWH08-1-0465, the Hartman Foundation and the Parkinson's Disease Foundation. V.L.V. is the recipient of an award from the Philippe Foundation for exchange programs between France and the Unites States. A.J. is the recipient of a postdoctoral fellowship from the Association Francaise contre les Myopathies (AFM).

\section{Disclosure}

The authors declare no conflicts of interest in this work.

\section{References}

1. Fonnum F. Glutamate: a neurotransmitter in mammalian brain. J Neurochem. 1984;42(1):1-11.

2. Collingridge GL, Singer W. Excitatory amino acid receptors and synaptic plasticity. Trends Pharmacol Sci. 1990;11(7):290-296.

3. Moriyama Y, Hayashi M, Yamada H, et al. Synaptic-like microvesicles, synaptic vesicle counterparts in endocrine cells, are involved in a novel regulatory mechanism for the synthesis and secretion of hormones. J Exp Biol. 2000;203(pt 1):117-125.

4. Lucas DR, Newhouse JP. The toxic effect of sodium L-glutamate on the inner layers of the retina. AMA Arch Ophthalmol. 1957;58(2): 193-201.

5. Olney JW. Brain lesions, obesity, and other disturbances in mice treated with monosodium glutamate. Science. 1969;164(880):719-721.

6. Curtis DR, Phillis JW, Watkins JC. Chemical excitation of spinal neurones. Nature. 1959;183(4661):611-612.

7. Olney JW. Toxic effects of glutamate and related amino acids on the developing central nervous system. In: Nyhan WH, ed. Heritable Disorders of Amino Acid Metabolism. New York: Wiley; 1974:501-512.

8. Maragakis NJ, Rothstein JD. Glutamate transporters: animal models to neurologic disease. Neurobiol Dis. 2004;15(3):461-473.

9. Ikonomidou C, Turski L. Excitotoxicity and neurodegenerative diseases. Curr Opin Neurol. 1995;8(6):487-497.

10. Hollmann M, Hartley M, Heinemann S. $\mathrm{Ca}^{2+}$ permeability of KA-AMPA - gated glutamate receptor channels depends on subunit composition. Science. 1991;252(5007):851-853.

11. Hume RI, Dingledine R, Heinemann SF. Identification of a site in glutamate receptor subunits that controls calcium permeability. Science. 1991;253(5023):1028-1031. 
12. Burnashev N, Monyer H, Seeburg PH, et al. Divalent ion permeability of AMPA receptor channels is dominated by the edited form of a single subunit. Neuron. 1992;8(1):189-198.

13. Sommer B, Keinanen K, Verdoorn TA, et al. Flip and flop: a cell-specific functional switch in glutamate-operated channels of the CNS. Science. 1990;249(4976):1580-1585.

14. Hollmann M, Heinemann S. Cloned glutamate receptors. Annu Rev Neurosci. 1994;17:31-108.

15. Choi DW. Ionic dependence of glutamate neurotoxicity. J Neurosci. 1987;7(2):369-379.

16. Kato K, Puttfarcken PS, Lyons WE, et al. Developmental time course and ionic dependence of kainate-mediated toxicity in rat cerebellar granule cell cultures. J Pharmacol Exp Ther. 1991;256(1):402-411.

17. Michaels RL, Rothman SM. Glutamate neurotoxicity in vitro: antagonist pharmacology and intracellular calcium concentrations. J Neurosci. 1990;10(1):283-292.

18. Choi DW, Hartley DM. Calcium and glutamate-induced cortical neuronal death. Res Publ Assoc Res Nerv Ment Dis. 1993;71:23-34.

19. Choi DW. Excitotoxic cell death. J Neurobiol. 1992;23(9): 1261-1276.

20. Del RP, Montiel T, Chagoya V, et al. Exacerbation of excitotoxic neuronal death induced during mitochondrial inhibition in vivo: relation to energy imbalance or ATP depletion? Neuroscience. 2007; 146(4):1561-1570.

21. Murphy TH, Miyamoto M, Sastre A, et al. Glutamate toxicity in a neuronal cell line involves inhibition of cystine transport leading to oxidative stress. Neuron. 1989;2(6):1547-1558.

22. Stanciu M, Wang Y, Kentor R, et al. Persistent activation of ERK contributes to glutamate-induced oxidative toxicity in a neuronal cell line and primary cortical neuron cultures. J Biol Chem. 2000;275(16): 12200-12206.

23. Schubert D, Piasecki D. Oxidative glutamate toxicity can be a component of the excitotoxicity cascade. J Neurosci. 2001;21(19):7455-7462.

24. Pow DV. Visualising the activity of the cystine-glutamate antiporter in glial cells using antibodies to aminoadipic acid, a selectively transported substrate. Glia. 2001;34(1):27-38.

25. Mizutani T, Sakamaki S, Tsuchiya N, et al. Amyotrophic lateral sclerosis with ophtalmoplegia and multisystem degeneration in patients on longterm use of respirators. Acta Neuropathol. 1992;84:372-377.

26. Rosen AD. Amyotrophic lateral sclerosis. Clinical features and prognosis. Arch Neurol. 1978;35(10):638-642.

27. Hirano A. Neuropathology of ALS: an overview. Neurology. 1996;47(4 Suppl 2):S63-S66.

28. Pasinelli P, Brown RH. Molecular biology of amyotrophic lateral sclerosis: insights from genetics. Nat Rev Neurosci. 2006;7(9):710-723.

29. Felbecker A, Camu W, Valdmanis PN, et al. Four familial ALS pedigrees discordant for two SOD1 mutations: are all SOD1 mutations pathogenic? J Neurol Neurosurg Psychiatry. 2010;81(5):572-577.

30. Pardo CA, Xu Z, Borchelt DR, et al. Superoxide dismutase is an abundant component in cell bodies, dendrites, and axons of motor neurons and in a subset of other neurons. Proc Natl Acad Sci U S A 1995;92(4):954-958.

31. Wong PC, Pardo CA, Borchelt DR, et al. An adverse property of a familial ALS-linked SOD1 mutation causes motor neuron disease characterized by vacuolar degeneration of mitochondria. Neuron. 1995; 14(6):1105-1116.

32. Gurney ME, Pu H, Chiu AY, et al. Motor neuron degeneration in mice that express a human $\mathrm{Cu}, \mathrm{Zn}$ superoxide dismutase mutation. Science. 1994;264(5166):1772-1775.

33. Bruijn LI, Becher MW, Lee MK, et al. ALS-linked SOD1 mutant G85R mediates damage to astrocytes and promotes rapidly progressive disease with SOD1-containing inclusions. Neuron. 1997;18(2):327-338.

34. Wang J, Slunt H, Gonzales V, et al. Copper-binding-site-null SOD1 causes ALS in transgenic mice: aggregates of non-native SOD1 delineate a common feature. Hum Mol Genet. 2003;12(21):2753-2764.

35. Avraham KB, Sugarman H, Rotshenker S, et al. Down's syndrome: morphological remodelling and increased complexity in the neuromuscular junction of transgenic $\mathrm{Cu} / \mathrm{Zn}$-superoxide dismutase mice. J Neurocytol. 1991;20(3):208-215.
36. van Den Bosch L, van Damme P, Bogaert E, et al. The role of excitotoxicity in the pathogenesis of amyotrophic lateral sclerosis. Biochim Biophys Acta. 2006;1762(11-12):1068-1082.

37. Rothstein JD, Martin LJ, Kuncl RW. Decreased glutamate transport by the brain and spinal cord in amyotrophic lateral sclerosis. $N$ Engl $J$ Med. 1992;326(22):1464-1468.

38. Wiedau-Pazos M, Goto JJ, Rabizadeh S, et al. Altered reactivity of superoxide dismutase in familial amyotrophic lateral sclerosis. Science. 1996;271(5248):515-518.

39. Yim MB, Kang JH, Yim HS, et al. A gain-of-function of an amyotrophic lateral sclerosis- associated $\mathrm{Cu}, \mathrm{Zn}$-superoxide dismutase mutant: an enhancement of free radical formation due to a decrease in $\mathrm{K}_{\mathrm{m}}$ for hydrogen peroxide. Proc Natl Acad Sci U S A. 1996;93(12):5709-5714.

40. Durham HD, Roy J, Dong L, et al. Aggregation of mutant $\mathrm{Cu} / \mathrm{Zn}$ superoxide dismutase proteins in a culture model of ALS. J Neuropathol Exp Neurol. 1997;56(5):523-530.

41. Kunst CB, Mezey E, Brownstein MJ, et al. Mutations in SOD1 associated with amyotrophic lateral sclerosis cause novel protein interactions. Nat Genet. 1997;15(1):91-94.

42. Estevez AG, Crow JP, Sampson JB, et al. Induction of nitric oxidedependent apoptosis in motor neurons by zinc-deficient superoxide dismutase. Science. 1999;286(5449):2498-2500.

43. Liu J, Lillo C, Jonsson PA, et al. Toxicity of familial ALS-linked SOD1 mutants from selective recruitment to spinal mitochondria. Neuron. 2004;43(1):5-17.

44. Shi P, Wei Y, Zhang J, et al. Mitochondrial dysfunction is a converging point of multiple pathological pathways in amyotrophic lateral sclerosis. J Alzheimers Dis. 2010;20 Suppl 2:S311-S324.

45. Kikuchi H, Almer G, Yamashita S, et al. Spinal cord endoplasmic reticulum stress associated with a microsomal accumulation of mutant superoxide dismutase-1 in an ALS model. Proc Natl Acad Sci USA. 2006;103(15):6025-6030.

46. Kostic V, Jackson-Lewis V, de Bilbao F, et al. Bcl-2: prolonging life in a transgenic mouse model of familial amyotrophic lateral sclerosis. Science. 1997;277(5325):559-562.

47. Li M, Ona VO, Guégan C, et al. Functional role of caspase-1 and caspase-3 in an ALS transgenic mouse model. Science. 2000;288(5464):335-339.

48. Young AB, Penney JB, Dauth GW, et al. Glutamate or aspartate as a possible neurotransmitter of cerebral corticofugal fibers in the monkey. Neurology. 1983;33(11):1513-1516.

49. O’Brien RJ, Fischbach GD. Modulation of embryonic chick motoneuron glutamate sensitivity by interneurons and agonists. J Neurosci. 1986;6(11):3290-3296.

50. Storm-Mathisen J, Otterson OP. Localisation of excitatory amino acid transmitters. In: Lodge D, editor. Excitatory Amino Acids in Health and Disease. Chichester: John Wiley and Sons; 1988:107-143.

51. Clement AM, Nguyen MD, Roberts EA, et al. Wild-type nonneuronal cells extend survival of SOD1 mutant motor neurons in ALS mice. Science. 2003;302(5642):113-117.

52. Beers DR, Henkel JS, Xiao Q, et al. Wild-type microglia extend survival in PU1 knockout mice with familial amyotrophic lateral sclerosis. Proc Natl Acad Sci U S A. 2006;103(43):16021-16026.

53. Boillee S, Yamanaka K, Lobsiger CS, et al. Onset and progression in inherited ALS determined by motor neurons and microglia. Science. 2006;312(5778):1389-1392.

54. Yamanaka K, Chun SJ, Boillee S, et al. Astrocytes as determinants of disease progression in inherited amyotrophic lateral sclerosis. Nat Neurosci. 2008;11(3):251-253.

55. Yamanaka K, Boillee S, Roberts EA, et al. Mutant SOD1 in cell types other than motor neurons and oligodendrocytes accelerates onset of disease in ALS mice. Proc Natl Acad Sci U S A. 2008;105(21):7594-7599.

56. Vargas MR, Pehar M, Cassina $P$, et al. Increased glutathione biosynthesis by Nrf2 activation in astrocytes prevents p75 NTR-dependent motor neuron apoptosis. J Neurochem. 2006;97(3):687-696.

57. Nagai M, Re DB, Nagata T, et al. Astrocytes expressing ALS-linked mutated SOD1 release factors selectively toxic to motor neurons. Nat Neurosci. 2007;10(5):615-622. 
58. Di Giorgio FP, Carrasco MA, Siao MC, et al. Non-cell autonomous effect of glia on motor neurons in an embryonic stem cell-based ALS model. Nat Neurosci. 2007;10(5):608-614.

59. Van Deerlin VM, Leverenz JB, Bekris LM, et al. TARDBP mutations in amyotrophic lateral sclerosis with TDP-43 neuropathology: a genetic and histopathological analysis. Lancet Neurol. 2008;7(5):409-416.

60. Kabashi E, Valdmanis PN, Dion P, et al. TARDBP mutations in individuals with sporadic and familial amyotrophic lateral sclerosis. Nat Genet. 2008;40(5):572-574.

61. Sreedharan J, Blair IP, Tripathi VB, et al. TDP-43 mutations in familial and sporadic amyotrophic lateral sclerosis. Science. 2008;319(5870): $1668-1672$.

62. Vance C, Rogelj B, Hortobagyi T, et al. Mutations in FUS, an RNA processing protein, cause familial amyotrophic lateral sclerosis type 6 . Science. 2009;323(5918):1208-1211.

63. Kwiatkowski TJ Jr, Bosco DA, LeClerc AL, et al. Mutations in the FUS/TLS gene on chromosome 16 cause familial amyotrophic lateral sclerosis. Science. 2009;323(5918):1205-1208.

64. Patten BM, Harati Y, Acosta L, et al. Free amino acid levels in amyotrophic lateral sclerosis. Ann Neurol. 1978;3(4):305-309.

65. Plaitakis A, Caroscio JT. Abnormal glutamate metabolism in amyotrophic lateral sclerosis. Ann Neurol. 1987;22(5):575-579.

66. Rothstein JD, Tsai G, Kuncl RW, et al. Abnormal excitatory amino acid metabolism in amyotrophic lateral sclerosis. Ann Neurol. 1990; 28(1):18-25.

67. IwasakiY, Ikeda K, Kinoshita M. Plasma amino acid levels in patients with amyotrophic lateral sclerosis. J Neurol Sci. 1992;107(2):219-222.

68. Shaw PJ, Forrest V, Ince PG, et al. CSF and plasma amino acid levels in motor neuron disease: elevation of CSF glutamate in a subset of patients. Neurodegeneration. 1995;4(2):209-216.

69. Meier DH, Schott KJ. Free amino acid pattern of cerebrospinal fluid in amyotrophic lateral sclerosis. Acta Neurol Scand. 1988;77(1):50-53.

70. Perry TL, Krieger C, Hansen S, et al. Amyotrophic lateral sclerosis: amino acid levels in plasma and cerebrospinal fluid. Ann Neurol. 1990; 28(1):12-17.

71. Spreux-Varoquaux O, Bensimon G, Lacomblez L, et al. Glutamate levels in cerebrospinal fluid in amyotrophic lateral sclerosis: a reappraisal using a new HPLC method with coulometric detection in a large cohort of patients. J Neurol Sci. 2002;193(2):73-78.

72. Camu W, Billiard M, Baldy-Moulinier M. Fasting plasma and CSF amino acid levels in amyotrophic lateral sclerosis: a subtype analysis. Acta Neurol Scand. 1993;88(1):51-55.

73. Andreadou E, Kapaki E, Kokotis P, et al. Plasma glutamate and glycine levels in patients with amyotrophic lateral sclerosis. In Vivo. 2008; 22(1):137-141.

74. Niebroj-Dobosz I, Janik P. Amino acids acting as transmitters in amyotrophic lateral sclerosis (ALS). Acta Neurol Scand. 1999;100(1): 6-11.

75. Fiszman ML, Ricart KC, Latini A, et al. In vitro neurotoxic properties and excitatory aminoacids concentration in the cerebrospinal fluid of amyotrophic lateral sclerosis patients. Relationship with the degree of certainty of disease diagnoses. Acta Neurol Scand. 2010;121(2): $120-126$.

76. Alexander GM, Deitch JS, Seeburger JL, et al. Elevated cortical extracellular fluid glutamate in transgenic mice expressing human mutant (G93 A) Cu/Zn superoxide dismutase. J Neurochem. 2000;74(4): $1666-1673$.

77. Tovar-y-Romo LB, Tapia R. Cerebral neurons of transgenic ALS mice are vulnerable to glutamate release stimulation but not to increased extracellular glutamate due to transport blockade. Exp Neurol. 2006; 199(2):281-290

78. Bendotti C, Tortarolo M, Suchak SK, et al. Transgenic SOD1 G93A mice develop reduced GLT-1 in spinal cord without alterations in cerebrospinal fluid glutamate levels. J Neurochem. 2001;79(4):737-746.

79. Askanas V, Marangos PJ, Engel WK. CSF from amyotrophic lateral sclerosis patients applied to motor neurons in culture fails to alter neuron-specific enolase. Neurology. 1981;31(9):1196-1197.
80. Iwasaki Y, Ikeda K, Shiojima T, et al. Amyotrophic lateral sclerosis cerebrospinal fluid is not toxic to cultured spinal motor neurons. Neurol Res. 1995;17(5):393-395.

81. Couratier P, Hugon J, Sindou P, et al. Cell culture evidence for neuronal degeneration in amyotrophic lateral sclerosis being linked to glutamate AMPA/kainate receptors. Lancet. 1993;341(8840):265-268.

82. Sen I, Nalini A, Joshi NB, et al. Cerebrospinal fluid from amyotrophic lateral sclerosis patients preferentially elevates intracellular calcium and toxicity in motor neurons via AMPA/kainate receptor. J Neurol Sci. 2005;235(1-2):45-54.

83. Anneser JM, Chahli C, Borasio GD. Protective effect of metabotropic glutamate receptor inhibition on amyotrophic lateral sclerosis-cerebrospinal fluid toxicity in vitro. Neuroscience. 2006;141(4):1879-1886.

84. Perry TL, Hansen S, Jones K. Brain glutamate deficiency in amyotrophic lateral sclerosis. Neurology. 1987;37(12):1845-1848.

85. Plaitakis A, Constantakakis E, Smith J. The neuroexcitotoxic amino acids glutamate and aspartate are altered in the spinal cord and brain in amyotrophic lateral sclerosis. Ann Neurol. 1988;24(3):446-449.

86. Tsai GC, Stauch-Slusher B, Sim L, et al. Reductions in acidic amino acids and $\mathrm{N}$-acetylaspartylglutamate in amyotrophic lateral sclerosis CNS. Brain Res. 1991;556(1):151-156.

87. Han J, Ma L. Study of the features of proton MR spectroscopy ((1) H-MRS) on amyotrophic lateral sclerosis. J Magn Reson Imaging. 2010;31(2):305-308.

88. Choi JK, Kustermann E, Dedeoglu A, et al. Magnetic resonance spectroscopy of regional brain metabolite markers in FALS mice and the effects of dietary creatine supplementation. Eur J Neurosci. 2009;30(11):2143-2150.

89. Spencer PS, Nunn PB, Hugon J, et al. Guam amyotrophic lateral sclerosis-parkinsonism-dementia linked to a plant excitant neurotoxin. Science. 1987;237(4814):517-522.

90. Bradley WG, Mash DC. Beyond Guam: the cyanobacteria/BMAA hypothesis of the cause of ALS and other neurodegenerative diseases. Amyotroph Lateral Scler. 2009;10 Suppl 2:7-20.

91. Lobner D. Mechanisms of beta-N-methylamino-L-alanine induced neurotoxicity. Amyotroph Lateral Scler. 2009;10 Suppl 2:56-60.

92. Nunn PB. Three phases of research on beta-N-methylamino-L-alanine (BMAA) - a neurotoxic amino acid. Amyotroph Lateral Scler. 2009; 10 Suppl 2:26-33.

93. Liu X, Rush T, Zapata J, et al. beta-N-methylamino-l-alanine induces oxidative stress and glutamate release through action on system Xc(-). Exp Neurol. 2009;217(2):429-433.

94. Vyas KJ, Weiss JH. BMAA - an unusual cyanobacterial neurotoxin. Amyotroph Lateral Scler. 2009;10 Suppl 2:50-55.

95. Nassif M, Matus S, Castillo K, et al. Amyotrophic lateral sclerosis pathogenesis: a journey through the secretory pathway. Antioxid Redox Signal. 2010;13(12)1955-1989.

96. Perl TM, Bedard L, Kosatsky T, et al. An outbreak of toxic encephalopathy caused by eating mussels contaminated with domoic acid. N Engl J Med. 1990;322(25):1775-1780.

97. Teitelbaum JS, Zatorre RJ, Carpenter S, et al. Neurologic sequelae of domoic acid intoxication due to the ingestion of contaminated mussels. N Engl J Med. 1990;322(25):1781-1787.

98. Tshala-Katumbay DD, Spencer PS. Chapter 18 Toxic disorders of the upper motor neuron system. Handb Clin Neurol. 2007;82: 353-372.

99. Bridges RJ, Stevens DR, Kahle JS, et al. Structure-function studies on N-oxalyl-diamino-dicarboxylic acids and excitatory amino acid receptors: evidence that beta-L-ODAP is a selective non-NMDA agonist. J Neurosci. 1989;9(6):2073-2079.

100. Rattray M, Bendotti C. Does excitotoxic cell death of motor neurons in ALS arise from glutamate transporter and glutamate receptor abnormalities? Exp Neurol. 2006;201(1):15-23.

101. Danbolt NC. Glutamate uptake. Prog Neurobiol. 2001;65(1):1-105.

102. Hertz L, Dringen R, Schousboe A, et al. Astrocytes: glutamate producers for neurons. J Neurosci Res. 1999;57(4):417-428. 
103. Tanaka K, Watase K, Manabe T, et al. Epilepsy and exacerbation of brain injury in mice lacking the glutamate transporter GLT-1. Science. 1997;276(5319):1699-1702.

104. Rothstein JD, van Kammen M, Levey AI, et al. Selective loss of glial glutamate transporter GLT-1 in amyotrophic lateral sclerosis. Ann Neurol. 1995;38(1):73-84.

105. Fray AE, Ince PG, Banner SJ, et al. The expression of the glial glutamate transporter protein EAAT2 in motor neuron disease: an immunohistochemical study. Eur J Neurosci. 1998;10(8):2481-2489.

106. Trotti D, Aoki M, Pasinelli P, et al. Amyotrophic lateral sclerosis-linked glutamate transporter mutant has impaired glutamate clearance capacity. J Biol Chem. 2001;276(1):576-582.

107. Honig LS, Chambliss DD, Bigio EH, et al. Glutamate transporter EAAT2 splice variants occur not only in ALS, but also in AD and controls. Neurology. 2000;55(8):1082-1088.

108. Lin CL, Bristol LA, Jin L, et al. Aberrant RNA processing in a neurodegenerative disease: the cause for absent EAAT2, a glutamate transporter, in amyotrophic lateral sclerosis. Neuron. 1998;20(3):589-602.

109. Aoki M, Lin CL, Rothstein JD, et al. Mutations in the glutamate transporter EAAT2 gene do not cause abnormal EAAT2 transcripts in amyotrophic lateral sclerosis. Ann Neurol. 1998;43(5): 645-653.

110. Canton T, Pratt J, Stutzmann JM, et al. Glutamate uptake is decreased tardively in the spinal cord of FALS mice. Neuroreport. 1998;9(5): 775-778.

111. Howland DS, Liu J, She Y, et al. Focal loss of the glutamate transporter EAAT2 in a transgenic rat model of SOD1 mutant-mediated amyotrophic lateral sclerosis (ALS). Proc Natl Acad Sci USA. 2002; 99(3):1604-1609.

112. Dunlop J, Beal MH, She Y, et al. Impaired spinal cord glutamate transport capacity and reduced sensitivity to riluzole in a transgenic superoxide dismutase mutant rat model of amyotrophic lateral sclerosis. J Neurosci. 2003;23(5):1688-1696.

113. Swanson RA, Liu J, Miller JW, et al. Neuronal regulation of glutamate transporter subtype expression in astrocytes. J Neurosci. 1997;17(3): 932-940.

114. Perego C, Vanoni C, Bossi M, et al. The GLT-1 and GLAST glutamate transporters are expressed on morphologically distinct astrocytes and regulated by neuronal activity in primary hippocampal cocultures. J Neurochem. 2000;75(3):1076-1084.

115. Levy LM, Lehre KP, Walaas SI, et al. Down-regulation of glial glutamate transporters after glutamatergic denervation in the rat brain. Eur J Neurosci. 1995;7(10):2036-2041.

116. Yang Y, Gozen O, Watkins A, et al. Presynaptic regulation of astroglial excitatory neurotransmitter transporter GLT1. Neuron. 2009;61(6): 880-894.

117. Guo H, Lai L, Butchbach ME, et al. Increased expression of the glial glutamate transporter EAAT2 modulates excitotoxicity and delays the onset but not the outcome of ALS in mice. Hum Mol Genet. 2003; 12(19):2519-2532.

118. Rothstein JD, Patel S, Regan MR, et al. Beta-lactam antibiotics offer neuroprotection by increasing glutamate transporter expression. Nature. 2005;433(7021):73-77.

119. Ganel R, Ho T, Maragakis NJ, et al. Selective up-regulation of the glial $\mathrm{Na}^{+}$-dependent glutamate transporter GLT1 by a neuroimmunophilin ligand results in neuroprotection. Neurobiol Dis. 2006;21(3): 556-567.

120. Pardo AC, Wong V, Benson LM, et al. Loss of the astrocyte glutamate transporter GLT1 modifies disease in SOD1(G93 A) mice. Exp Neurol. 2006;201(1):120-130.

121. Volterra A, Trotti D, Racagni G. Glutamate uptake is inhibited by arachidonic acid and oxygen radicals via two distinct and additive mechanisms. Mol Pharmacol. 1994;46(5):986-992.

122. Volterra A, Trotti D, Tromba C, et al. Glutamate uptake inhibition by oxygen free radicals in rat cortical astrocytes. J Neurosci. 1994; 14(5 Pt 1):2924-2932.

123. Trotti D, Rolfs A, Danbolt NC, et al. SOD1 mutants linked to amyotrophic lateral sclerosis selectively inactivate a glial glutamate transporter. Nat Neurosci. 1999;2(9):848.
124. Boston-Howes W, Gibb SL, Williams EO, et al. Caspase-3 cleaves and inactivates the glutamate transporter EAAT2. J Biol Chem. 2006; 281(20):14076-14084.

125. Tortarolo M, Crossthwaite AJ, Conforti L, et al. Expression of SOD1 G93A or wild-type SOD1 in primary cultures of astrocytes downregulates the glutamate transporter GLT-1: lack of involvement of oxidative stress. J Neurochem. 2004;88(2):481-493.

126. Lepore AC, Rauck B, Dejea C, et al. Focal transplantation-based astrocyte replacement is neuroprotective in a model of motor neuron disease. Nature Neurosci. 2008;11(11):1294-1301.

127. Reichelt W, Stabel-Burow J, Pannicke T, et al. The glutathione level of retinal Muller glial cells is dependent on the high-affinity sodiumdependent uptake of glutamate. Neuroscience. 1997;77(4):1213-1224.

128. Pellerin L, Magistretti PJ. Glutamate uptake into astrocytes stimulates aerobic glycolysis: a mechanism coupling neuronal activity to glucose utilization. Proc Natl Acad Sci U S A. 1994;91(22):10625-10629.

129. Rothstein JD, Jin L, Dykes-Hoberg M, et al. Chronic inhibition of glutamate uptake produces a model of slow neurotoxicity. Proc Natl Acad Sci U S A. 1993;90(14):6591-6595.

130. Okazaki S, Nishida Y, Kawai H, et al. Acute neurotoxicity of L-glutamate induced by impairment of the glutamate uptake system. Neurochem Res. 1996;21(10):1201-1207.

131. Matyja E, Nagańska E, Taraszewska A, et al. The mode of spinal motor neurons degeneration in a model of slow glutamate excitotoxicity in vitro. Folia Neuropathol. 2005;43(1):7-13.

132. Massieu L, Morales-Villagran A, Tapia R. Accumulation of extracellular glutamate by inhibition of its uptake is not sufficient for inducing neuronal damage: an in vivo microdialysis study. J Neurochem. 1995; 64(5):2262-2272.

133. Obrenovitch TP, Urenjak J. Altered glutamatergic transmission in neurological disorders: from high extracellular glutamate to excessive synaptic efficacy. Prog Neurobiol. 1997;51(1):39-87.

134. Tovar YRL, Santa-Cruz LD, Zepeda A, et al. Chronic elevation of extracellular glutamate due to transport blockade is innocuous for spinal motoneurons in vivo. Neurochem Int. 2009;54(3-4):186-191.

135. Shaw PJ, Ince PG, Johnson M, et al. The quantitative autoradiographic distribution of [3H]MK-801 binding sites in the normal human spinal cord. Brain Res. 1991;539(1):164-168.

136. Stewart GR, Olney JW, Pathikonda M, et al. Excitotoxicity in the embryonic chick spinal cord. Ann Neurol. 1991;30(6):758-766.

137. Williams TL, Ince PG, Oakley AE, et al. An immunocytochemical study of the distribution of AMPA selective glutamate receptor subunits in the normal human motor system. Neuroscience. 1996;74(1):185-198.

138. Yin HZ, Park DD, Lindsay AD, et al. Spinal cord neurons are vulnerable to rapidly triggered kainate neurotoxicity in vitro. Brain Res. 1995;689(2):265-270.

139. Carriedo SG, Sensi SL, Yin HZ, et al. AMPA exposures induce mitochondrial $\mathrm{Ca}(2+)$ overload and ROS generation in spinal motor neurons in vitro. J Neurosci. 2000;20(1):240-250.

140. van Den Bosch L, Vandenberghe W, Klaassen H, et al. Ca(2+)permeable AMPA receptors and selective vulnerability of motor neurons. J Neurol Sci. 2000;180(1-2):29-34.

141. Chinnery RM, Shaw PJ, Ince PG, et al. Autoradiographic distribution of binding sites for the non-NMDA receptor antagonist [3H]CNQX in human motor cortex, brainstem and spinal cord. Brain Res. 1993; 630(1-2):75-81.

142. Shaw PJ, Ince PG, Matthews JN, et al. N-methyl-D-aspartate (NMDA) receptors in the spinal cord and motor cortex in motor neuron disease: a quantitative autoradiographic study using [3H]MK-801. Brain Res. 1994;637(1-2):297-302.

143. Shaw PJ, Chinnery RM, Ince PG. [3H]D-aspartate binding sites in the normal human spinal cord and changes in motor neuron disease: a quantitative autoradiographic study. Brain Res. 1994;655(1-2):195-201.

144. Shaw PJ, Chinnery RM, Ince PG. Non-NMDA receptors in motor neuron disease (MND): a quantitative autoradiographic study in spinal cord and motor cortex using [3H]CNQX and [3H]kainate. Brain Res. 1994;655(1-2):186-194. 
145. Urca G, Urca R. Neurotoxic effects of excitatory amino acids in the mouse spinal cord: quisqualate and kainate but not N-methyl-Daspartate induce permanent neural damage. Brain Res. 1990;529(1-2): $7-15$.

146. Delfs JR, Saroff DM, Nishida Y, et al. Effects of NMDA and its antagonists on ventral horn cholinergic neurons in organotypic roller tube spinal cord cultures. J Neural Transm. 1997;104(1):31-51.

147. Ikonomidou C, Qin QY, Labruyere J, et al. Motor neuron degeneration induced by excitotoxin agonists has features in common with those seen in the SOD-1 transgenic mouse model of amyotrophic lateral sclerosis. J Neuropathol Exp Neurol. 1996;55(2):211-224.

148. Saroff D, Delfs J, Kuznetsov D, et al. Selective vulnerability of spinal cord motor neurons to non-NMDA toxicity. Neuroreport. 2000;11(5): 1117-1121.

149. Corona JC, Tapia R. AMPA receptor activation, but not the accumulation of endogenous extracellular glutamate, induces paralysis and motor neuron death in rat spinal cord in vivo. $J$ Neurochem. 2004; 89(4):988-997.

150. Sun H, Kawahara Y, Ito K, et al. Slow and selective death of spinal motor neurons in vivo by intrathecal infusion of kainic acid: implications for AMPA receptor-mediated excitotoxicity in ALS. J Neurochem. 2006;98(3):782-791.

151. Furuyama T, Kiyama H, Sato K, et al. Region-specific expression of subunits of ionotropic glutamate receptors (AMPA-type, KA-type and NMDA receptors) in the rat spinal cord with special reference to nociception. Brain Res Mol Brain Res. 1993;18(1-2):141-151.

152. Petralia RS, Wang YX, Mayat E, et al. Glutamate receptor subunit 2-selective antibody shows a differential distribution of calciumimpermeable AMPA receptors among populations of neurons. J Comp Neurol. 1997;385(3):456-476.

153. Shaw PJ, Williams TL, Slade JY, et al. Low expression of GluR2 AMPA receptor subunit protein by human motor neurons. Neuroreport. 1999;10(2):261-265.

154. Heath PR, Tomkins J, Ince PG, et al. Quantitative assessment of AMPA receptor mRNA in human spinal motor neurons isolated by laser capture microdissection. Neuroreport. 2002;13(14):1753-1757.

155. Kawahara Y, Kwak S, Sun H, et al. Human spinal motoneurons express low relative abundance of GluR2 mRNA: an implication for excitotoxicity in ALS. J Neurochem. 2003;85(3):680-689.

156. Williams TL, Ince PG, Oakley AE, et al. An immunocytochemical study of the distribution of AMPA selective glutamate receptor subunits in the normal human motor system. Neuroscience. 1996;74(1): 185-198.

157. Williams TL, Day NC, Ince PG, et al. Calcium-permeable alphaamino-3-hydroxy-5-methyl-4-isoxazole propionic acid receptors: a molecular determinant of selective vulnerability in amyotrophic lateral sclerosis. Ann Neurol. 1997;42(2):200-207.

158. Vandenberghe W, Bindokas VP, Miller RJ, et al. Subcellular localization of calcium-permeable AMPA receptors in spinal motoneurons. Eur J Neurosci. 2001;14(2):305-314.

159. Nagy GG, Al-Ayyan M, Andrew D, et al. Widespread expression of the AMPA receptor GluR2 subunit at glutamatergic synapses in the rat spinal cord and phosphorylation of GluR1 in response to noxious stimulation revealed with an antigen-unmasking method. J Neurosci. 2004;24(25):5766-5777.

160. Iihara K, Joo DT, Henderson J, et al. The influence of glutamate receptor 2 expression on excitotoxicity in Glur2 null mutant mice. J Neurosci. 2001;21(7):2224-2239.

161. Vandenberghe W, Ihle EC, Patneau DK, et al. AMPA receptor current density, not desensitization, predicts selective motoneuron vulnerability. J Neurosci. 2000;20(19):7158-7166.

162. Vandenberghe W, Robberecht W, Brorson JR. AMPA receptor calcium permeability, GluR2 expression, and selective motoneuron vulnerability. J Neurosci. 2000;20(1):123-132.

163. Krieger C, Lanius RA, Pelech SL, et al. Amyotrophic lateral sclerosis: the involvement of intracellular $\mathrm{Ca}^{2+}$ and protein kinase C. Trends Pharmacol Sci. 1996;17(3):114-120.
164. Anneser JM, Horstmann S, Weydt P, et al. Activation of metabotropic glutamate receptors delays apoptosis of chick embryonic motor neurons in vitro. Neuroreport. 1998;9(9):2039-2043.

165. Pizzi M, Benarese M, Boroni F, et al. Neuroprotection by metabotropic glutamate receptor agonists on kainate-induced degeneration of motor neurons in spinal cord slices from adult rat. Neuropharmacology. 2000;39(5):903-910.

166. Valerio A, Ferrario M, Paterlini M, et al. Spinal cord mGlula receptors: possible target for amyotrophic lateral sclerosis therapy. Pharmacol Biochem Behav. 2002;73(2):447-454.

167. Laslo P, Lipski J, Funk GD. Differential expression of Group I metabotropic glutamate receptors in motoneurons at low and high risk for degeneration in ALS. Neuroreport. 2001;12(9):1903-1908.

168. Brusa R, Zimmermann F, Koh DS, et al. Early-onset epilepsy and postnatal lethality associated with an editing-deficient GluR-B allele in mice. Science. 1995;270(5242):1677-1680.

169. Kuner R, Groom AJ, Bresink I, et al. Late-onset motoneuron disease caused by a functionally modified AMPA receptor subunit. Proc Natl Acad Sci U S A. 2005;102(16):5826-5831.

170. Feldmeyer D, Kask K, Brusa R, et al. Neurological dysfunctions in mice expressing different levels of the Q/R site-unedited AMPAR subunit GluR-B. Nat Neurosci. 1999;2(1):57-64.

171. Jia Z, Agopyan N, Miu P, et al. Enhanced LTP in mice deficient in the AMPA receptor GluR2. Neuron. 1996;17(5):945-956.

172. Greger IH, Khatri L, Ziff EB. RNA editing at arg607 controls AMPA receptor exit from the endoplasmic reticulum. Neuron. 2002;34(5): 759-772.

173. Greger IH, Khatri L, Kong X, et al. AMPA receptor tetramerization is mediated by Q/R editing. Neuron. 2003;40(4):763-774.

174. Hideyama T, Yamashita T, Suzuki T, et al. Induced loss of ADAR2 engenders slow death of motor neurons from Q/R site-unedited GluR2. J Neurosci. 2010;30(36):11917-11925.

175. Siklos L, Engelhardt J, Harati Y, et al. Ultrastructural evidence for altered calcium in motor nerve terminals in amyotropic lateral sclerosis. Ann Neurol. 1996;39(2):203-216.

176. Siklos L, Engelhardt JI, Alexianu ME, et al. Intracellular calcium parallels motoneuron degeneration in SOD-1 mutant mice. J Neuropathol Exp Neurol. 1998;57(6):571-587.

177. Allaoua H, Chaudieu I, Krieger C, et al. Alterations in spinal cord excitatory amino acid receptors in amyotrophic lateral sclerosis patients. Brain Res. 1992;579(1):169-172.

178. Virgo L, De Belleroche J. Induction of the immediate early gene c-jun in human spinal cord in amyotrophic lateral sclerosis with concomitant loss of NMDA receptor NR-1 and glycine transporter mRNA. Brain Res. 1995;676:196-204.

179. Spalloni A, Origlia N, Sgobio C, et al. Postsynaptic alteration of NR2 A subunit and defective autophosphorylation of alphaCaMKII at threonine-286 contribute to abnormal plasticity and morphology of upper motor neurons in presymptomatic SOD1G93 A mice, a murine model for amyotrophic lateral sclerosis. Cereb Cortex. 2010. [Epub ahead of print].

180. Wang R, Zhang D. Memantine prolongs survival in an amyotrophic lateral sclerosis mouse model. Eur J Neurosci. 2005;22(9):2376-2380.

181. Aracava Y, Pereira EF, Maelicke A, et al. Memantine blocks alpha7* nicotinic acetylcholine receptors more potently than n-methyl-Daspartate receptors in rat hippocampal neurons. J Pharmacol Exp Ther. 2005;312(3):1195-1205.

182. Seeman P, Caruso C, Lasaga M. Memantine agonist action at dopamine D2High receptors. Synapse. 2008;62(2):149-153.

183. Van DP, Leyssen M, Callewaert G, et al. The AMPA receptor antagonist NBQX prolongs survival in a transgenic mouse model of amyotrophic lateral sclerosis. Neurosci Lett. 2003;343(2):81-84.

184. Tortarolo M, Grignaschi G, Calvaresi N, et al. Glutamate AMPA receptors change in motor neurons of SOD1G93 A transgenic mice and their inhibition by a noncompetitive antagonist ameliorates the progression of amytrophic lateral sclerosis-like disease. J Neurosci Res. 2006;83(1):134-146. 
185. Tateno M, Sadakata H, Tanaka M, et al. Calcium-permeable AMPA receptors promote misfolding of mutant SOD1 protein and development of amyotrophic lateral sclerosis in a transgenic mouse model. Hum Mol Genet. 2004;13(19):2183-2196.

186. Van DP, Braeken D, Callewaert G, et al. GluR2 deficiency accelerates motor neuron degeneration in a mouse model of amyotrophic lateral sclerosis. J Neuropathol Exp Neurol. 2005;64(7):605-612.

187. Spalloni A, Albo F, Ferrari F, et al. $\mathrm{Cu} / \mathrm{Zn}$-superoxide dismutase (GLY93 - >ALA) mutation alters AMPA receptor subunit expression and function and potentiates kainate-mediated toxicity in motor neurons in culture. Neurobiol Dis. 2004;15(2):340-350.

188. Laslo P, Lipski J, Nicholson LF, et al. GluR2 AMPA receptor subunit expression in motoneurons at low and high risk for degeneration in amyotrophic lateral sclerosis. Exp Neurol. 2001;169(2):461-471.

189. Takuma H, Kwak S, Yoshizawa T, et al. Reduction of GluR2 RNA editing, a molecular change that increases calcium influx through AMPA receptors, selective in the spinal ventral gray of patients with amyotrophic lateral sclerosis. Ann Neurol. 1999;46(6):806-815.

190. Kawahara Y, Ito K, Sun H, et al. Glutamate receptors: RNA editing and death of motor neurons. Nature. 2004;427(6977):801.

191. Kwak S, Kawahara Y. Deficient RNA editing of GluR2 and neuronal death in amyotropic lateral sclerosis. $J$ Mol Med. 2005;83(2): 110-120.

192. Kawahara Y, Sun H, Ito K, et al. Underediting of GluR2 mRNA, a neuronal death inducing molecular change in sporadic ALS, does not occur in motor neurons in ALS1 or SBMA. Neurosci Res. 2006;54(1): 11-14.

193. Tomiyama M, Rodriguez-Puertas R, Cortes R, et al. Flip and flop splice variants of AMPA receptor subunits in the spinal cord of amyotrophic lateral sclerosis. Synapse. 2002;45(4):245-249.

194. Roy J, Minotti S, Dong L, et al. Glutamate potentiates the toxicity of mutant $\mathrm{Cu} / \mathrm{Zn}$-superoxide dismutase in motor neurons by postsynaptic calcium-dependent mechanisms. J Neurosci. 1998;18(23): 9673-9684.

195. Spalloni A, Pascucci T, Albo F, et al. Altered vulnerability to kainate excitotoxicity of transgenic-Cu/Zn SOD1 neurones. Neuroreport. 2004;15(16):2477-2480.

196. Kruman II, Pedersen WA, Springer JE, et al. ALS-linked Cu/Zn-SOD mutation increases vulnerability of motor neurons to excitotoxicity by a mechanism involving increased oxidative stress and perturbed calcium homeostasis. Exp Neurol. 1999;160(1):28-39.

197. Raoul C, Estevez A, Nishimune H, et al. Motoneuron death triggered by a specific pathway downstream of Fas. potentiation by ALS-linked SOD1 mutations. Neuron. 2002;35(6):1067-1083.

198. Van Damme P, Bogaert E, Dewil M, et al. Astrocytes regulate GluR2 expression in motor neurons and their vulnerability to excitotoxicity. Proc Natl Acad Sci U S A. 2007;104(37):14825-14830.

199. Pieri M, Gaetti C, Spalloni A, et al. alpha-Amino-3-hydroxy-5-methylisoxazole-4-propionate receptors in spinal cord motor neurons are altered in transgenic mice overexpressing human $\mathrm{Cu}, \mathrm{Zn}$ superoxide dismutase (Gly93->Ala) mutation. Neuroscience. 2003;122(1): 47-58.

200. Bogaert E, Van Damme P, Poesen K, et al. VEGF protects motor neurons against excitotoxicity by upregulation of GluR2. Neurobiol Aging. 2010;31(12):2185-2191.

201. Azzouz M, Ralph GS, Storkebaum E, et al. VEGF delivery with retrogradely transported lentivector prolongs survival in a mouse ALS model. Nature. 2004;429(6990):413-417.

202. Storkebaum E, Lambrechts D, Dewerchin M, et al. Treatment of motoneuron degeneration by intracerebroventricular delivery of VEGF in a rat model of ALS. Nat Neurosci. 2005;8(1):85-92.

203. Anneser JM, Chahli C, Ince PG, et al. Glial proliferation and metabotropic glutamate receptor expression in amyotrophic lateral sclerosis. J Neuropathol Exp Neurol. 2004;63(8):831-840.

204. Vermeiren C, Hemptinne I, Vanhoutte N, et al. Loss of metabotropic glutamate receptor-mediated regulation of glutamate transport in chemically activated astrocytes in a rat model of amyotrophic lateral sclerosis. J Neurochem. 2006;96(3):719-731.
205. Vermeiren C, Najimi M, Vanhoutte N, et al. Acute up-regulation of glutamate uptake mediated by mGluR $5 \mathrm{a}$ in reactive astrocytes. J Neurochem. 2005;94(2):405-416.

206. Van DP, Callewaert G, Eggermont J, et al. Chloride influx aggravates $\mathrm{Ca} 2+-$ dependent AMPA receptor-mediated motoneuron death. J Neurosci. 2003;23(12):4942-4950.

207. Magoul R, Onteniente B, Geffard M, et al. Anatomical distribution and ultrastructural organization of the GABAergic system in the rat spinal cord. An immunocytochemical study using anti-GABA antibodies. Neuroscience. 1987;20(3):1001-1009.

208. Powers RK, Binder MD. Input-output functions of mammalian motoneurons. Rev Physiol Biochem Pharmacol. 2001;143:137-263.

209. Vucic S, Kiernan MC. Upregulation of persistent sodium conductances in familial ALS. J Neurol Neurosurg Psychiatry. 2010;81(2): 222-227.

210. Kanai K, Kuwabara S, Misawa S, et al. Altered axonal excitability properties in amyotrophic lateral sclerosis: impaired potassium channel function related to disease stage. Brain. 2006;129(pt 4): 953-962.

211. Pambo-Pambo A, Durand J, Gueritaud JP. Early excitability changes in lumbar motoneurons of transgenic SOD1G85R and SOD1G(93 A-Low) mice. J Neurophysiol. 2009;102(6):3627-3642.

212. Boerio D, Kalmar B, Greensmith L, et al. Excitability properties of mouse motor axons in the mutant SOD1(G93 A) model of amyotrophic lateral sclerosis. Muscle Nerve. 2010;41(6):774-784.

213. Fadda E, Danysz W, Wroblewski JT, et al. Glycine and D-serine increase the affinity of N-methyl-D-aspartate sensitive glutamate binding sites in rat brain synaptic membranes. Neuropharmacology. 1988;27(11):1183-1185

214. Shleper M, Kartvelishvily E, Wolosker H. D-serine is the dominant endogenous coagonist for NMDA receptor neurotoxicity in organotypic hippocampal slices. J Neurosci. 2005;25(41):9413-9417.

215. Sasabe J, Chiba T, Yamada M, et al. D-Serine is a key determinant of glutamate toxicity in amyotrophic lateral sclerosis. EMBO J. 2007; 26(18):4149-4159.

216. Shaw PJ, Ince PG. Glutamate, excitotoxicity and amyotrophic lateral sclerosis. J Neurol. 1997;244 Suppl 2:S3-S14.

217. Clapham DE. Calcium signaling. Cell. 1995;80(2):259-268.

218. Bezprozvanny I. Calcium signaling and neurodegenerative diseases. Trends Mol Med. 2009;15(3):89-100.

219. Marambaud P, Dreses-Werringloer U, Vingtdeux V. Calcium signaling in neurodegeneration. Mol Neurodegener. 2009;4:20.

220. Grosskreutz J, Van Den BL, Keller BU. Calcium dysregulation in amyotrophic lateral sclerosis. Cell Calcium. 2010;47(2):165-174.

221. Tymianski M, Charlton MP, Carlen PL, et al. Source specificity of early calcium neurotoxicity in cultured embryonic spinal neurons. J Neurosci. 1993;13(5):2085-2104.

222. Sattler R, Charlton MP, Hafner M, et al. Distinct influx pathways, not calcium load, determine neuronal vulnerability to calcium neurotoxicity. J Neurochem. 1998;71(6):2349-2364.

223. Urushitani M, Nakamizo T, Inoue R, et al. N-methyl-D-aspartate receptor-mediated distinct from chronic neurotoxicity after $\mathrm{Ca}(2+)$ influx. J Neurosci Res. 2001;63(5):377-387.

224. Guatteo E, Carunchio I, Pieri M, et al. Altered calcium homeostasis in motor neurons following AMPA receptor but not voltage-dependent calcium channels' activation in a genetic model of amyotrophic lateral sclerosis. Neurobiol Dis. 2007;28(1):90-100.

225. Alexianu ME, Ho BK, Mohamed AH, et al. The role of calcium-binding proteins in selective motoneuron vulnerability in amyotrophic lateral sclerosis. Ann Neurol. 1994;36(6):846-858.

226. Beers DR, Ho BK, Siklos L, et al. Parvalbumin overexpression alters immune-mediated increases in intracellular calcium, and delays disease onset in a transgenic model of familial amyotrophic lateral sclerosis. J Neurochem. 2001;79(3):499-509.

227. White RJ, Reynolds IJ. Mitochondria and $\mathrm{Na}+/ \mathrm{Ca} 2+$ exchange buffer glutamate-induced calcium loads in cultured cortical neurons. J Neurosci. 1995;15(2):1318-1328. 
228. Jonas P, Racca C, Sakmann B, et al. Differences in $\mathrm{Ca} 2+$ permeability of AMPA-type glutamate receptor channels in neocortical neurons caused by differential GluR-B subunit expression. Neuron. 1994;12(6):1281-1289.

229. Grosskreutz J, Haastert K, Dewil M, et al. Role of mitochondria in kainate-induced fast $\mathrm{Ca} 2+$ transients in cultured spinal motor neurons. Cell Calcium. 2007;42(1):59-69.

230. Damiano M, Starkov AA, Petri S, et al. Neural mitochondrial Ca2+ capacity impairment precedes the onset of motor symptoms in G93 A Cu/Zn-superoxide dismutase mutant mice. J Neurochem. 2006;96(5):1349-1361.

231. Rao SD, Yin HZ, Weiss JH. Disruption of glial glutamate transport by reactive oxygen species produced in motor neurons. J Neurosci. 2003;23(7):2627-2633.

232. Kim HJ, Im W, Kim S, et al. Calcium-influx increases SOD1 aggregates via nitric oxide in cultured motor neurons. Exp Mol Med. 2007;39(5):574-582.

233. Kanki R, Nakamizo T, Yamashita H, et al. Effects of mitochondrial dysfunction on glutamate receptor-mediated neurotoxicity in cultured rat spinal motor neurons. Brain Res. 2004;1015(1-2):73-81.

234. Van Westerlaak MG, Joosten EA, Gribnau AA, et al. Chronic mitochondrial inhibition induces glutamate-mediated corticomotoneuron death in an organotypic culture model. Exp Neurol. 2001;167(2): 393-400

235. Berridge MJ, Bootman MD, Roderick HL. Calcium signalling: dynamics, homeostasis and remodelling. Nat Rev Mol Cell Biol. 2003;4(7):517-529.

236. Kanekura K, Suzuki H, Aiso S, et al. ER stress and unfolded protein response in amyotrophic lateral sclerosis. Mol Neurobiol. 2009;39(2):81-89.

237. Jahn K, Grosskreutz J, Haastert K, et al. Temporospatial coupling of networked synaptic activation of AMPA-type glutamate receptor channels and calcium transients in cultured motoneurons. Neuroscience. 2006;142(4):1019-1029.

238. Van Den Bosch L, Verhoeven K, De SH, et al. Calcium handling proteins in isolated spinal motoneurons. Life Sci. 1999;65(15):1597-1606.

239. Ruiz A, Matute C, Alberdi E. Endoplasmic reticulum $\mathrm{Ca}(2+)$ release through ryanodine and $\mathrm{IP}(3)$ receptors contributes to neuronal excitotoxicity. Cell Calcium. 2009;46(4):273-281.

240. Frandsen A, Schousboe A. Excitatory amino acid-mediated cytotoxicity and calcium homeostasis in cultured neurons. J Neurochem. 1993;60(4):1202-1211.

241. Canton T, Pratt J, Stutzmann JM, et al. Glutamate uptake is decreased tardively in the spinal cord of FALS mice. Neuroreport. 1998;9(5): 775-778.

242. Kawamata H, Manfredi G. Mitochondrial dysfunction and intracellular calcium dysregulation in ALS. Mech Ageing Dev. 2010.
243. Bensimon G, Lacomblez L, Meininger V. A controlled trial of riluzole in amyotrophic lateral sclerosis. ALS/Riluzole Study Group. N Engl J Med. 1994;330(9):585-591.

244. Lacomblez L, Bensimon G, Leigh PN, et al. A confirmatory doseranging study of riluzole in ALS. ALS/Riluzole Study Group-II. Neurology. 1996;47(6 Suppl 4):S242-S250.

245. Doble A. The pharmacology and mechanism of action of riluzole. Neurology. 1996;47(6 Suppl 4):S233-S241.

246. Azbill RD, Mu X, Springer JE. Riluzole increases high-affinity glutamate uptake in rat spinal cord synaptosomes. Brain Res. 2000;871(2): 175-180.

247. Bensimon G, Lacomblez L, Meininger V. A controlled trial of riluzole in amyotrophic lateral sclerosis. ALS/Riluzole Study Group. N Engl J Med. 1994;330(9):585-591.

248. Gurney ME, Cutting FB, Zhai P, et al. Benefit of vitamin E, riluzole, and gabapentin in a transgenic model of familial amyotrophic lateral sclerosis. Ann Neurol. 1996;39(2):147-157.

249. Ghadge GD, Slusher BS, Bodner A, et al. Glutamate carboxypeptidase II inhibition protects motor neurons from death in familial amyotrophic lateral sclerosis models. Proc Natl Acad Sci U S A. 2003;100(16): 9554-9559.

250. Cudkowicz ME, Shefner JM, Schoenfeld DA, et al. A randomized, placebo-controlled trial of topiramate in amyotrophic lateral sclerosis. Neurology. 2003;61(4):456-464.

251. de CM, Pinto S, Costa J, et al. A randomized, placebo-controlled trial of memantine for functional disability in amyotrophic lateral sclerosis. Amyotroph Lateral Scler. 2010;11(5):456-460.

252. Gredal O, Werdelin L, Bak S, et al. A clinical trial of dextromethorphan in amyotrophic lateral sclerosis. Acta Neurol Scand. 1997;96(1): $8-13$.

253. Eisen A, Stewart H, Schulzer M, et al. Anti-glutamate therapy in amyotrophic lateral sclerosis: a trial using lamotrigine. Can J Neurol Sci. 1993;20(4):297-301.

254. Mazzini L, Mora G, Balzarini C, et al. The natural history and the effects of gabapentin in amyotrophic lateral sclerosis. J Neurol Sci. 1998;160 Suppl 1:S57-S63.

255. McDermott MP, Rowland LP. ALS defeats gabapentin: reflections on another failed treatment. Neurology. 2001;56(7):826-827.

256. Boston-Howes W, Williams EO, Bogush A, et al. Nordihydroguaiaretic acid increases glutamate uptake in vitro and in vivo: therapeutic implications for amyotrophic lateral sclerosis. Exp Neurol. 2008;213(1): 229-237.

257. Corona JC, Romo LB, Tapia R. Glutamate excitotoxicity and therapeutic targets for amyotrophic lateral sclerosis. Expert Opin Ther Targets. 2007;11(11):1415-1428.
Journal of Receptor, Ligand and Channel Research

\section{Publish your work in this journal}

The Journal of Receptor, Ligand and Channel Research is an international, peer-reviewed, open access, online journal. The journal welcomes laboratory and clinical findings in the fields of biological receptors, ligands, channel and signal transduction research including: receptors and signalling; ligands; transporters, pores and channels; binding and activation; receptor

\section{Dovepress}

regulation; role of receptors in diseases and their treatment; molecular basis of membrane structure and functions; molecular models of membranes. The manuscript management system is completely online and includes a very quick and fair peer-review system. Visit http://www.dovepress.com/ testimonials.php to read real quotes from published authors. 